\title{
Surgimento e consolidação da Semana Internacional de Arqueologia Discentes MAE-USP: uma reflexão
}

\author{
Kelly Brandão* \\ Aline Oliveira * * \\ Meliam Gaspar*** \\ Maurício André da Silva**** \\ Renato Saad Panunzio***** \\ Renata Estevam***** \\ Emerson Nobre ****** \\ Elaine Farias Veloso Hirata $* * * * * * *$
}

BRANDÃO, K. et al. Surgimento e consolidação da Semana Internacional de Arqueologia Discentes MAE-USP: uma reflexão. R. Museu Arq. Etn. 34: 1-25, 2020.

Resumo: Este artigo discute e reflete sobre a criação e consolidação da Semana Internacional de Arqueologia Discentes (SIA), do Museu de Arqueologia e Etnologia da Universidade de São Paulo (MAE-USP), que surgiu em 2007 e ocorre com frequência bianual. Organizada de forma aberta e colaborativa por discentes do Museu, a SIA se tornou um espaço de articulação, troca de conhecimentos e experiências, que desempenha papel fundamental na formação de futuros profissionais engajados com a ciência e a gestão do patrimônio arqueológico no cenário nacional da Arqueologia. Ao longo das várias edições, o evento se profissionalizou e ganhou marca internacional, com a criação de um protocolo dinâmico e democrático para que estudantes possam realizar trabalhos conjuntos e de maior inserção institucional. Organizada por discentes e voltada para pessoas interessadas em geral, a SIA potencializou seu espírito aberto e o diálogo crescente com diferentes grupos que demandam novas práticas e posturas do fazer arqueológico. Por meio de entrevistas, questionários, análises de documentação e de nossa experiência pessoal, trazemos um olhar sobre a história da SIA e seu papel na trajetória acadêmica de discentes e no Museu como um todo. Esperamos que essa reflexão possa contribuir com o estímulo para a continuidade e o surgimento de outros eventos semelhantes pelo país.

Palavras-chave: Eventos científicos; Arqueologia; Estudantes; Organização.

\footnotetext{
*Doutoranda pelo Programa de Arqueologia da Universidade de São Paulo (MAE-USP). <kellybrand@gmail.com>

** Mestranda pelo Programa de Arqueologia da Universidade de São Paulo (USP). <alineffeitoza@gmail.com>

*** Doutora pelo Programa de Arqueologia da Universidade de São Paulo (USP). <meliamvgaspar@gmail.com>

****Doutorando pelo Programa de Arqueologia da Universidade de São Paulo (USP). <mauricio.andre.silva@usp.br>

***** Mestre pelo Programa de Arqueologia da Universidade de São Paulo (USP). <rspanunzio.dm@gmail.com>
}

\footnotetext{
******Mestra pelo Programa de Arqueologia da Universidade de São Paulo (USP). Pesquisadora colaboradora no Grupo de Pesquisa em Educação Patrimonial e Arqueologia da Universidade do Sul de Santa Catarina (Grupep-Arqueologia).<reestevams@gmail.com> ******* Doutorando pelo Programa de Arqueologia da Universidade de São Paulo (USP). <emersom.nobre@gmail.com> ******** Museu de Arqueologia e Etnologia da Universidade de São Paulo (MAE-USP), Coordenadora da VI Semana Internacional de Arqueologia Discentes. <ehirata.veloso@gmail.com>
} 


\section{Introdução}

$\triangle$ Semana Internacional de Arqueologia (SIA) do Museu de Arqueologia e Etnologia da Universidade de São Paulo (MAE-USP) foi criada por discentes ${ }^{1}$ do Museu com os objetivos de promover diálogo e interação entre pesquisas desenvolvidas dentro e fora da instituição, ampliar a convivência institucional e proporcionar experiências com organização de um evento acadêmico-científico a estudantes.

Os percursos da pós-graduação são muitas vezes solitários, por isso, ao longo de suas várias edições, o evento almejou aproximar discentes, docentes e servidories técniques, assim como discutir pontos (tanto comuns quanto divergentes) entre distintas áreas de pesquisa. A ideia foi crescendo, outras atividades foram incluídas, os temas discutidos se diversificaram e a presença de estudantes provenientes de todo o país e palestrantes de diversas partes do mundo se ampliou. Criada por estudantes para estudantes, a SIA ganhou lugar de destaque no calendário da Arqueologia no Brasil e atraiu a atenção de toda a comunidade arqueológica e interessades em geral. Sua programação reflete mudanças de interesse das novas gerações de pesquisadories da área, assim como evidencia engajamentos contemporâneos da disciplina. Após sua sexta edição, propomos aqui uma reflexão sobre as origens do evento, seu desenvolvimento ao longo dos anos e sua contribuição para a formação de estudantes.

Este artigo está circunscrito pelo olhar des autories, que participaram de diferentes edições, mas que procuraram incluir pontos de vistas de participantes de todas as edições por meio de questionários enviados eletronicamente, pela análise da documentação das comissões organizadoras e por materiais de divulgação (Nishida \& Plens 2007). Ressaltamos o caráter coletivo da organização discente, não

1 Adotamos a linguagem não binária no artigo, substituímos os marcadores linguísticos binários de gênero ("o" para masculino e "a" para feminino) por "elu/ile", para contemplarmos diferentes identidades de gênero e para afirmarmos o compromisso político com a diversidade da vida. personalizando a discussão ou as ações. Nenhuma narrativa é isenta, por isso é bem-vindo que outres organizadores do evento narrem essa história a partir de seus pontos de vista. O intuito deste artigo é contribuir para que ideias reverberem, contribuam e inspirem outros eventos científicos pelo país organizados por discentes, tanto os que já existem como os que podem ser criados $^{2}$.

\section{Histórico do evento}

A partir do desejo coletivo de integração entre discentes de Arqueologia brasileira e do Mediterrâneo no MAE-USP, passaram a ser organizados grupos de estudo com encontros semanais ou mensais para discutir abordagens teórico-metodológicas e para compartilhar dúvidas ou conhecimentos sobre temas transversais de suas pesquisas, independentemente da área específica em que atuavam. Esses encontros também fortaleceram discentes enquanto coletivo dentro da instituição, já que muitos não moravam em São Paulo e viajavam esporadicamente para cumprir disciplinas, enquanto outros (por não terem bolsas de estudos) trabalhavam fora do Museu. A convivência mais próxima entre discentes também permitiu a discussão de questões relacionadas ao cotidiano enquanto estudantes da pós-graduação da instituição.

Com o passar do tempo, a necessidade de formalização desses encontros surgiu para que a emissão de certificados e convites formais para docentes de outras instituições virem palestrar fossem possíveis. Assim, um grupo de discentes se mobilizou para a organização da I Semana de Arqueologia, inspirada em eventos similares que já ocorriam em outras unidades da Universidade de São Paulo (USP), como a Semana de Oceanografia. Organizado por Paula Nishida, Claudia Plens, Juliana S. Machado

2 Artigos sobre eventos científicos nas mais diferentes áreas têm sido escritos com esses objetivos (Tomazou \& Powel 2007; Corpas et al. 2008; Paz et al., 2014; Faria et al. 2019), o que mostra a importância desse balanço na área da Arqueologia também. 
e Lucas Bueno ${ }^{3}$ e com o auxílio formal do professor Levy Figuti, o evento ocorreu entre 23 e 27 de abril de 2007 nas próprias dependências do MAE-USP. A edição mobilizou o Museu de maneira bastante positiva, com o apoio da direção, funcionáries e docentes. Ocorreram palestras de ex-estudantes e professores externos ao MAE, com temas que o corpo estudantil considerava importantes na época (Quadro 1). A estruturação das comunicações orais em eixos temáticos também mostrou a diversidade de assuntos que eram trabalhados dentro do Museu, como patrimônio, estudos da tecnologia lítica e cerâmica, métodos/técnicas e teoria, etnoarqueologia, zooarqueologia, ações educativas e curadoria.

Docentes do MAE foram convidades para debater as sessões de comunicação em que havia estudantes do Museu e de outras instituições, pois desde então as inscrições já eram abertas para pessoas de outros programas de pós-graduação. Discentes da graduação puderam expor seus trabalhos de iniciação científica na forma de pôster. A I Semana de Arqueologia contou ainda com a publicação de artigos no Suplemento 8 da Revista de Arqueologia do MAE (Figuti, Plens \& Nishida 2009), que incluiu algumas palestras des convidades e apresentações de estudantes.

Entre a primeira e a segunda edição houve um intervalo de quatro anos. A construção da II Semana de Arqueologia está diretamente vinculada à retomada da organização estudantil e de sua formalização com a representação

3 Todas as informações referentes a discentes organizadories das Semanas de Arqueologia foram obtidas a partir da documentação oficial gerada pelos eventos, como cadernos de resumo, atas de reuniões e projetos de financiamento. A documentação sobre a primeira edição é a mais escassa, sabemos que durante a organização dos eventos, demais colegas se envolveram em diferentes momentos e também deixaram suas contribuições, mesmo que não registradas nos documentos oficiais. discente nos colegiados do MAE-USP, assim como das assembleias discentes. Foram doze organizadories: Eduardo Kazuo Tamanaha, Fabio Guaraldo Almeida, Fernando Ozório de Almeida, Irmina Doneux Santos, João Estevam de Argos, Lorena Garcia, Marjorie Lima, Patrícia Fischer, Regina Helena Rezende, Rodrigo Suñer, Silvio Luiz Cordeiro e Tatiana Bina. Sob a coordenação da professora Maria Isabel D'Agostino Fleming, a II SA contou também com dez colaboradories, ocorreu entre 30 de maio e 3 de junho de 2011 e foi realizada nas dependências da Faculdade de Educação da USP (FE-USP). Houve a preocupação de manter o encontro no primeiro semestre do ano para evitar sobreposições com calendários de outros congressos de Arqueologia no país.

As mesas redondas realizadas nesta edição tiveram como temas: monumentalidade; espaço, organização social e tecnologia; Arqueologia pública e Arqueologia de contrato (Quadro 2). Novamente, foram publicados artigos nos Anais do evento como suplemento número $11 \mathrm{da}$ Revista do Museu de Arqueologia e Etnologia (Fleming 2011).

A continuidade da Semana foi incrementada com a inclusão de outras atividades na programação. Foi realizada uma mostra fotográfica que reuniu quarenta fotos de trabalhos de campo enviadas por participantes e selecionadas pela comissão organizadora, e que até hoje permanece nos corredores do MAE-USP.

Em parceria com o Cinema da Universidade de São Paulo (Cinusp) também foi realizada a I Mostra Audiovisual Internacional em Arqueologia (Maia), organizada pelo Dr. Silvio Cordeiro, com a apresentação de dezessete filmes acompanhados por debates com arqueólogues, documentaristas, produtories audiovisuais e educadories. 
Surgimento e consolidação da Semana Internacional de Arqueologia Discentes MAE-USP: uma reflexão R. Museu Arq. Etn., 34: 1-25, 2020.

\begin{tabular}{|c|c|}
\hline \multicolumn{2}{|c|}{ I Semana de Arqueologia MAE-USP } \\
\hline Palestrante & Tema \\
\hline $\begin{array}{l}\text { André Prous } \\
\text { (Universidade Federal de Minas Gerais - } \\
\text { UFMG) }\end{array}$ & As pinturas em cerâmica Tupi-Guarani \\
\hline $\begin{array}{l}\text { Marcia Arcuri } \\
\text { (MAE-USP) }\end{array}$ & $\begin{array}{l}\text { O Tahuantinsuyu e as tradições pré-Incas: o poder das huacas } \\
\text { nas relações centro-periferia de Cuzco }\end{array}$ \\
\hline $\begin{array}{l}\text { Dirse Kern } \\
\text { (Museu Paraense Emílio Goeldi) }\end{array}$ & $\begin{array}{l}\text { A análise e interpretação dos solos e sedimentos nas } \\
\text { pesquisas arqueológicas }\end{array}$ \\
\hline $\begin{array}{l}\text { Sheila Mendonça de Souza } \\
\text { (Fundação Oswaldo Cruz) }\end{array}$ & $\begin{array}{l}\text { O potencial dos estudos bioarqueológicos: um olhar } \\
\text { além dos ossos }\end{array}$ \\
\hline $\begin{array}{l}\text { Dominique Gallois } \\
\text { (Faculdade de Filosofia, Letras e Ciências } \\
\text { Humanas - FFLCH-USP) }\end{array}$ & $\begin{array}{l}\text { Desafios para os inventários do patrimônio cultural imaterial } \\
\text { de povos indígenas }\end{array}$ \\
\hline $\begin{array}{l}\text { Gilson Rambelli (Universidade Estadual de } \\
\text { Campinas - Unicamp) }\end{array}$ & Arqueologia subaquática no Brasil \\
\hline $\begin{array}{l}\text { Marco Aurélio de Mais (Universidade do Sul } \\
\text { de Santa Catarina - Unisul) }\end{array}$ & A utilização de isótopos estáveis em contextos arqueológicos \\
\hline $\begin{array}{l}\text { Verônica Wesolowski } \\
\text { (Fundação Oswaldo Cruz) }\end{array}$ & $\begin{array}{l}\text { Nem só de peixes e mariscos: indícios de consumo de vegetais } \\
\text { em sambaquis do litoral norte de Santa Catarina - Primeiros } \\
\text { insights a partir da análise de micro resíduos em } \\
\text { cálculos dentários }\end{array}$ \\
\hline $\begin{array}{l}\text { Paulo César Fonseca Giannini } \\
\text { (Instituto de Geociências - IGC-USP) }\end{array}$ & $\begin{array}{l}\text { Cenários deposicionais para a ocupação sambaquieira na costa } \\
\text { sul catarinense }\end{array}$ \\
\hline $\begin{array}{l}\text { Fábio Vergara Cerqueira } \\
\text { (Universidade Federal de Pelotas - UFPel) }\end{array}$ & $\begin{array}{l}\text { Iconografia Clássica e Arqueologia Histórica: das relações } \\
\text { entre o texto, o suporte material e a imagem na interpretação } \\
\text { da pintura dos vasos áticos do período dos séculos VI a IV a.C. }\end{array}$ \\
\hline
\end{tabular}

Quadro 1: Palestrantes e temas da I Semana de Arqueologia MAE-USP.

A experiência de pessoas que participaram da segunda edição foi importante para a organização e o acolhimento de discentes ingressantes. Cabe destacar que, a partir de 2011, o corpo estudantil passou a ter maior interesse pelos rumos e decisões da instituição, pela participação de forma ativa nos colegiados do MAE-USP e posicionamento público enquanto coletivo sobre temas do patrimônio e prática arqueológica no país. ${ }^{4}$

4 Nota de posicionamento sobre populações tradicionais atingidas por obras de grandes empreendimentos disponível em: <https://bit.ly/32STflk>. Acesso em: 24/07/2020; Posicionamento dos/das Discentes do Museu de Arqueologia e Etnologia da USP ao IPHAN: não é essa a mudança que queremos disponível em: 〈https://bit.ly/2BtibLn>. Acesso em: 24/07/2020; Nota de Posicionamento dos Discentes MAEUSP em relação à Greve de 2016 disponível em: <https://bit.ly/3jx1q37>. Acesso em: 24/07/2020.
A III Semana Internacional de Arqueologia "André Penin" Discentes MAE-USP, foi rebatizada para incluir a internacionalização no nome do encontro, devido a participação de palestrantes internacionais, público de diversas regiões do país, e explicitar sua organização pelo corpo discente. Ao incluir o nome de André Penin, pessoas que organizaram essa edição homenagearam o colega pesquisador da Universidade Federal de Rondônia (Unir), discente egresso do Museu cuja vida foi abruptamente interrompida.

A comissão organizadora foi composta por Agda Sardinha, Alessandro Mortaio Gregori, Alex Martire, Ana Paula Moreli Tauhyl, Camila Jácome, Débora Leonel Soares, Erêndira Oliveira, Guilherme Mongeló, Jaqueline 
Belletti, João Carlos Moreno de Sousa, Márcia Lika Hattori, Márjorie Lima, Mauricio André da Silva, Meliam Viganó Gaspar, Milena Acha, Pedro Henrique de A. B. Damin, Roberto Montenegro Perrota, Tatiana Bina, Tatiane Souza, Thiago Trindade e Tiago Atorre. O encontro ocorreu entre 22 e 27 de abril de 2013, com a coordenação da professora Verônica Wesolowski. Contou com a participação de 21 estudantes, três colaboradories, e buscou ampliar as discussões por meio do convite de pesquisadories internacionais. Com a ampliação da Semana e o maior número de discentes envolvides, foi possível angariar verba com diferentes agências de fomento. $\mathrm{O}$ aumento no número de participantes também fez com que fosse necessário buscar outro espaço físico que comportasse o público: o prédio da FFLCH-USP.

\begin{tabular}{|c|c|c|}
\hline \multicolumn{3}{|c|}{ II Semana de Arqueologia MAE-USP } \\
\hline Palestrante & Tema & Mesa \\
\hline $\begin{array}{l}\text { José Oliver } \\
\text { (University College London - } \\
\text { UCL, Inglaterra) }\end{array}$ & $\begin{array}{l}\text { Caciques y Cemíes: iconos políticos-religiosos } \\
\text { y el poderio de los caciques antillanos }\end{array}$ & Palestra de abertura \\
\hline $\begin{array}{l}\text { Scott J. Allen } \\
\text { (Universidade Federal de } \\
\text { Pernambuco -UFPE) }\end{array}$ & $\begin{array}{l}\text { Monumentos e Monumentalidade na e } \\
\text { da Arqueologia Histórica }\end{array}$ & \multirow{3}{*}{$\begin{array}{l}\text { Que "monumento" é este? Arque- } \\
\text { ologia do Monumento ou Monu- } \\
\text { mentalidade na Arqueologia }\end{array}$} \\
\hline $\begin{array}{l}\text { Maria Dulce Barcellos Gaspar } \\
\text { de Oliveira } \\
\text { (Universidade Federal do Rio } \\
\text { de Janeiro - UFRJ) }\end{array}$ & - & \\
\hline $\begin{array}{l}\text { Marcelo Rede } \\
\text { (FFLCH-USP) }\end{array}$ & $\begin{array}{l}\text { A Assíria Monumental: glórias e infortú- } \\
\text { nios de uma perspectiva arqueológica }\end{array}$ & \\
\hline $\begin{array}{l}\text { Lucas Bueno } \\
\text { (Instituto de Biologia - IB-USP) }\end{array}$ & - & \multirow{3}{*}{$\begin{array}{l}\text { Espaço, Organização Social e } \\
\text { Tecnologia: uma abordagem } \\
\text { interdisciplinar }\end{array}$} \\
\hline $\begin{array}{l}\text { Marta Amoroso } \\
\text { (FFLCH-USP) }\end{array}$ & $\begin{array}{l}\text { O ambientalismo e as novas negociações } \\
\text { dos Mura do Rio Preto do Igapó-Açu (AM) }\end{array}$ & \\
\hline $\begin{array}{l}\text { Elaine Veloso Hirata } \\
\text { (MAE-USP) }\end{array}$ & $\begin{array}{l}\text { A paisagem construída no Mediterrâneo } \\
\text { Antigo: entre a Arqueologia e a História }\end{array}$ & \\
\hline $\begin{array}{l}\text { Maria Clara Migliacio } \\
\text { (Instituto de Patrimônio } \\
\text { Histórico e Artístico Nacional } \\
\text { IPHAN-Brasília) }\end{array}$ & \multirow{3}{*}{-} & \multirow{3}{*}{$\begin{array}{l}\text { Arqueologia Pública \& } \\
\text { Arqueologia de Contrato: } \\
\text { o papel do arqueólogo na } \\
\text { gestão do patrimônio }\end{array}$} \\
\hline $\begin{array}{l}\text { Paulo Zanettini } \\
\text { (Zanettini Arqueologia) }\end{array}$ & & \\
\hline $\begin{array}{l}\text { Fabíola Andréa Silva } \\
\text { (MAE-USP) }\end{array}$ & & \\
\hline $\begin{array}{l}\text { Guillermo Acosta Ochoa } \\
\text { (Universidad Nacional } \\
\text { Autónoma de México - } \\
\text { Unam, México) }\end{array}$ & $\begin{array}{l}\text { Gestión y análisis de datos de excavación } \\
\text { para el estudio de áreas de actividad } \\
\text { mediante el empleo de sistemas de } \\
\text { información geográfica (SIG/GIS) }\end{array}$ & Palestra de encerramento \\
\hline
\end{tabular}

Quadro 2: Palestrantes e temas da II Semana de Arqueologia MAE-USP. 
As mesas redondas exploraram temas relacionados a Arqueologia de gênero, Arqueologia pré-colombiana e interdisciplinaridade (Quadro 3). Como debate de abertura, estudantes refletiram com diferentes profissionais sobre o papel da Arqueologia preventiva no cenário brasileiro e seus impactos nas populações locais, estimulades pelos dilemas éticos das pesquisas. Para tal discussão, foi realizada uma pesquisa a respeito dos dilemas e sonhos de discentes em torno da carreira, para repensar a dicotomia entre trabalhos realizados na academia e no contrato. A apresentação de comunicações orais para pós-graduandes e formades e de pôsteres para graduandes foi mantida. Foi organizada uma segunda mostra de fotografias: sobre a diversidade da pesquisa arqueológica desenvolvida pelo MAE-USP no tempo e no espaço. Ocorreu uma nova mostra de filmes da Maia, realizada no sábado seguinte ao evento, no emblemático prédio do Centro Universitário Maria Antônia, no centro de São Paulo. Artigos das apresentações e palestras foram publicados no Suplemento número 20 da Revista de Arqueologia (Wesolowski et al., 2015).

A partir da experiência da III SIA, discentes produziram o "Guia Prático de Organização de Eventos Acadêmicos." para elaboração de eventos discentes, com enfoque no exercício colaborativo e na tomada conjunta de decisões. Elaborar qualquer atividade com muitas vozes é ao mesmo tempo um grande desafio e uma experiência enriquecedora. Com esse material, a SIA

5 Esse Guia é atualizado a cada edição. Ele funciona como ponte entre as organizações das semanas, que instruem discentes que não têm experiência em organização de eventos e permite que organizadories possam visualizar como as edições anteriores foram pensadas, com dicas de divisão de tarefas, de como elaborar e acompanhar projetos e prazos para solicitação de verbas, prestações de contas, entre outros pontos. Isso permite que haja uma troca entre as edições e que organizadories possam deixar conselhos e caminhos para que a nova comissão não perca tempo nem se prejudique comecando do zero. Também foi criada uma pasta na nuvem, onde atas de discussões, material de divulgação, orçamentos e contratos são compartilhados e deixados à disposição para consulta. ampliou seu espaço democrático de construção, apresentando caminhos para criar diálogos com docentes coordenadores e outras pessoas da instituição para que as ideias do corpo discente reverberem no formato e temas da Semana.

A IV Semana Internacional de Arqueologia foi organizada por Bruno Sanches Ranzani da Silva, Bruno Pastre, Davi Garcia, Danilo Tabone (in memoriam), Duane Mota, Emerson Nobre, Erêndira Oliveira, Guilherme Mongeló, Isabel Catanio, Laura Furquim, Mariana Cristante, Marina Di Giusto, Rafael de Almeida Lopes, Renan Falcheti, Patrícia Marinho, Silvia Leal e Thiago Kater. Ocorreu entre 8 e 12 de junho de 2015, com a coordenação do professor Vagner Cavalheiro Porto e três colaboradories. O local foi a recém-inaugurada Biblioteca Brasiliana Guita e José Mindlin e a Casa de Cultura Japonesa na USP. Essa edição da SIA ocorreu durante a comemoração dos vinte e cinco anos do MAE-USP, o que resultou em uma mostra fotográfica relacionada ao tema e homenageou pessoas ligadas ao MAE que haviam falecido recentemente ${ }^{6}$.

A IV SIA englobou a atual discussão a respeito do papel da Arqueologia no presente, com a proposta de refletir sobre seus impactos na sociedade e como colaborar para (re)pensar a situação social no mundo contemporâneo. Em consonância aos objetivos expostos, o evento foi composto por duas palestras (uma de abertura e outra de encerramento), quatro mesas redondas temáticas, um fórum de discussão, além de diversas comunicações avulsas, que foram agrupadas por afinidades temáticas. As mesas redondas trataram sobre a temática africana, etnoarqueologia, bioarqueologia, métodos arqueológicos, enquanto um fórum foi proposto para discutir Arqueologia em zonas de conflito (Quadro 4).É importante destacar que em todas as mesas, pela primeira vez, houve também a participação de discentes de mestrado e de

6 As professoras Dorath Pinto Uchôa e Margarida Andreatta, e o discente Danilo Tabone. 
doutorado, que apresentaram suas pesquisas em diálogo direto com discentes e pesquisadories mais experientes. Esse modelo foi chamado de "comunicação redonda", em uma tentativa de integrar mais convidadies e estudantes.
Os artigos dos Anais foram publicados em um ebook (Porto et al. 2019) devido a diversas questões com a publicação da Revista de Arqueologia do MAE que adiaram bastante a publicação.

\begin{tabular}{|c|c|c|}
\hline \multicolumn{3}{|c|}{ III Semana Internacional de Arqueologia “André Penin” Discentes MAE-USP } \\
\hline Palestrante & Tema & Mesa \\
\hline $\begin{array}{l}\text { Stephen Silliman } \\
\text { (University of Massachussets, Boston, } \\
\text { Estados Unidos) }\end{array}$ & $\begin{array}{l}\text { Change, continuity, and collaboration: } \\
\text { studying indigenous history in colonial } \\
\text { North America }\end{array}$ & $\begin{array}{l}\text { Palestra de } \\
\text { abertura }\end{array}$ \\
\hline $\begin{array}{l}\text { Claire Smith } \\
\text { (Flinders University, Austrália) }\end{array}$ & $\begin{array}{l}\text { Growing a career in Archaeology in a global } \\
\text { world: challenges, opportunities and strategies }\end{array}$ & Palestra extra \\
\hline $\begin{array}{l}\text { Fred Limp } \\
\text { (University of Arkansas, Student Alumni } \\
\text { Association - UARK-SAA, Estados Unidos) }\end{array}$ & $\begin{array}{l}\text { Looking at the past with new eyes: applica- } \\
\text { tions of new digital geomatics technologies } \\
\text { for the recording, analysis and preservation of } \\
\text { world heritage }\end{array}$ & $\begin{array}{l}\text { Palestra de } \\
\text { encerramento }\end{array}$ \\
\hline $\begin{array}{l}\text { Márcia Bezerra } \\
\text { (Programa de Pós-Graduação em Antropologia da } \\
\text { Universidade Federal do Pará - PPGA-UFPA) }\end{array}$ & \multirow{4}{*}{-} & \multirow{4}{*}{$\begin{array}{l}\text { Debate: } \\
\text { Arqueologia em } \\
\text { construção }\end{array}$} \\
\hline $\begin{array}{l}\text { Paulo Zanettini } \\
\text { (Zanettini Arqueologia) }\end{array}$ & & \\
\hline $\begin{array}{l}\text { Solange Caldarelli } \\
\text { (Scientia Consultoria Científica) }\end{array}$ & & \\
\hline $\begin{array}{l}\text { Coletivo de alunos do Programa de Pós- } \\
\text { Graduação em Arqueologia (PPARQ) MAE-USP }\end{array}$ & & \\
\hline $\begin{array}{l}\text { Marta Mega de Andrade } \\
\text { (Museu Nacional - MN-UFRJ) }\end{array}$ & $\begin{array}{l}\text { O "gênero" e o espaço: entre o uso e a } \\
\text { ordem, uma categoria de análise? }\end{array}$ & \multirow{3}{*}{$\begin{array}{l}\text { Arqueologia de } \\
\text { Gênero e suas } \\
\text { implicações } \\
\text { teóricas e práticas }\end{array}$} \\
\hline $\begin{array}{l}\text { Vânia Carvalho } \\
\text { (Museu Paulista - MP-USP) }\end{array}$ & $\begin{array}{l}\text { Curadoria e pesquisa sobre as relações de } \\
\text { gênero no espaço da casa }\end{array}$ & \\
\hline $\begin{array}{l}\text { Loredana Ribeiro } \\
\text { (UFPel) }\end{array}$ & $\begin{array}{l}\text { Gênero e etnografia arqueológica: } \\
\text { seguindo artefatos, escritos, narrativas... }\end{array}$ & \\
\hline $\begin{array}{l}\text { Jürgen Golte } \\
\text { (Universidad Nacional Mayor de San Marcos, Peru) }\end{array}$ & $\begin{array}{l}\text { Entender la cosmología del intermedio } \\
\text { temprano andino por la iconografía Moche }\end{array}$ & \multirow{3}{*}{$\begin{array}{l}\text { Diferentes } \\
\text { olhares sobre a } \\
\text { cultura material: } \\
\text { cosmovisão e } \\
\text { identidade na } \\
\text { América Pré- } \\
\text { Colombiana }\end{array}$} \\
\hline $\begin{array}{l}\text { Javier Nastri } \\
\text { (Universidad de Buenos Aires - UBA, Argentina) }\end{array}$ & $\begin{array}{l}\text { El estudio de los órdenes sociales } \\
\text { Precolombinos a través de la iconografía: } \\
\text { claves interpretativas }\end{array}$ & \\
\hline $\begin{array}{l}\text { Quirino Olivera Núñez } \\
\text { (Museo de Sipán - Peru) }\end{array}$ & Arqueología en la Alta Amazonía de Perú & \\
\hline $\begin{array}{l}\text { Paulo César Fonseca Giannini } \\
\text { (IGC-USP) }\end{array}$ & $\begin{array}{l}\text { Distribuição tempo-espacial e estratigrafia } \\
\text { de sambaquis na costa centro-sul de Santa } \\
\text { Catarina: a influência do fator geológico } \\
\end{array}$ & \multirow{3}{*}{$\begin{array}{l}\text { A Terra, a vida e } \\
\text { a humanidade: } \\
\text { o diálogo inter e } \\
\text { multidisciplinar } \\
\text { da Arqueologia }\end{array}$} \\
\hline $\begin{array}{l}\text { Rui Murrieta } \\
\text { (IB-USP) }\end{array}$ & $\begin{array}{l}\text { Das interfaces entre Arqueologia, } \\
\text { Ciências Naturais e Antropologia }\end{array}$ & \\
\hline $\begin{array}{l}\text { Patrick Le Roux } \\
\text { (Université de Paris XIII, França) }\end{array}$ & Apports et limites de l'épigraphie & \\
\hline
\end{tabular}

Quadro 3: Palestrantes e temas da III Semana Internacional de Arqueologia (SIA) “André Penin” Discentes MAE-USP. 
Surgimento e consolidação da Semana Internacional de Arqueologia Discentes MAE-USP: uma reflexão R. Museu Arq. Etn., 34: 1-25, 2020.

\begin{tabular}{|c|c|}
\hline \multicolumn{2}{|c|}{ IV Semana Internacional de Arqueologia Discentes MAE-USP } \\
\hline Palestrante & Mesa \\
\hline $\begin{array}{l}\text { Ulpiano Bezerra de Menezes } \\
\text { (USP) }\end{array}$ & Palestra de abertura \\
\hline \begin{tabular}{|l} 
Julio Moracen Naranjo \\
(Universidade Federal de São Paulo - Unifesp)
\end{tabular} & $\begin{array}{l}\text { Arqueologia da África e da } \\
\text { diáspora africana }\end{array}$ \\
\hline $\begin{array}{l}\text { Luis Cláudio Symanski } \\
\text { (UFMG) }\end{array}$ & $\begin{array}{l}\text { Arqueologia da África e da } \\
\text { diáspora africana }\end{array}$ \\
\hline \begin{tabular}{|l|}
$\begin{array}{l}\text { Dorothy Lippert } \\
\text { (Museu Nacional de História Natural, Smithsonian Institute, Estados Unidos) }\end{array}$ \\
José Pablo Baraybar \\
(Diretor da Equipe Peruana de Antropologia Forense)
\end{tabular} & \multirow{4}{*}{$\begin{array}{l}\text { Fórum "Arqueologia em zonas } \\
\text { de conflito" }\end{array}$} \\
\hline $\begin{array}{l}\text { Rafael Abreu } \\
\text { (Doutorando MAE-USP. Grupo de Trabalho Perus. Secretaria de Direitos } \\
\text { Humanos da Presidência da República); Grupo de Trabalho do Araguaia } \\
\text { (Ministério da Justiça/Secretaria de Direitos Humanos/Ministério da Defesa) }\end{array}$ & \\
\hline \begin{tabular}{|l|} 
Bruna Cigaran Rocha \\
(Universidade Federal do Oeste do Pará - Ufopa) \\
\end{tabular} & \\
\hline \begin{tabular}{|l|} 
Miguel Alejandro Aguilar Diaz \\
(Universidad de los Andes, Colômbia) \\
\end{tabular} & \\
\hline $\begin{array}{l}\text { Gustavo Gabriel Politis } \\
\text { (Universidad Nacional de la Plata, Argentina) }\end{array}$ & \multirow{2}{*}{$\begin{array}{l}\text { Etnoarqueologias e arqueologias } \\
\text { do tempo presente }\end{array}$} \\
\hline $\begin{array}{l}\text { Juliana Salles Machado } \\
\text { (USP) }\end{array}$ & \\
\hline \begin{tabular}{|l|} 
Sheila Ferraz Mendonça de Souza \\
(Fundação Oswaldo Cruz)
\end{tabular} & $\begin{array}{l}\text { Bioarqueologia e Arqueologia } \\
\text { Funerária }\end{array}$ \\
\hline $\begin{array}{l}\text { Sérgio Francisco Monteiro da Silva } \\
\text { (UFPE) }\end{array}$ & $\begin{array}{l}\text { Bioarqueologia e Arqueologia } \\
\text { Funerária }\end{array}$ \\
\hline $\begin{array}{l}\text { Mariano Bonomo } \\
\text { (Universidad Nacional de la Plata, Argentina) }\end{array}$ & $\begin{array}{l}\text { Métodos contemporâneos } \\
\text { na Arqueologia }\end{array}$ \\
\hline \begin{tabular}{|l}
$\begin{array}{l}\text { Daniela M. Kökler } \\
\text { (Universidade Federal de Sergipe - UFS) }\end{array}$ \\
\end{tabular} & $\begin{array}{l}\text { Métodos contemporâneos } \\
\text { na Arqueologia }\end{array}$ \\
\hline $\begin{array}{l}\text { Luis Guillermo Lumbreras } \\
\text { (Universidad Nacional Mayor de San Marcos, Peru) }\end{array}$ & Palestra de encerramento \\
\hline
\end{tabular}

Quadro 4: Palestrantes e temas da IV Semana Internacional de Arqueologia Discentes MAE-USP.

A V Semana Internacional de Arqueologia Discentes MAE-USP foi realizada de 8 a 13 de maio de 2017, novamente na Faculdade de Educação (FE/USP). A comissão contou com 25 organizadories: Ana Carolina Pellegrini, Bruna Laura Alves Carvalho, Daniela Ortega, Eliane Chim, Emerson Nobre, Fabrício Bernardes, Glauco Constantino, Henrique Antônio Valadares Costa, Henrique de Sena Kozlowski, Isabela da Silva Müller, Jéssica
Mendes Cardoso, Jordana Batista Barbosa, Kelly Brandão, Laura Furquim, Letícia Ribeiro, Letícia Correa, Marcony Lopes Alves, Marianne Sallum, Marina Di Giusto, Marjori Pacheco Dias, Meliam Gaspar, Nicolás Batalla, Renata Estevam da Silva, Renato Saad Panunzio e Rodrigo Angeles. Contou também com o auxílio de dois colaboradories e coordenação do professor Camilo de Mello Vasconcellos. Foram realizadas cinco mesas redondas com 
as seguintes temáticas: comércio ilegal de bens arqueológicos; gestão de acervos arqueológicos; e arqueologia da paisagem (Quadro 5). Ocorreu também o Fórum de Arqueologia e Gênero, no qual participaram cerca de 70 pessoas. Durante o fórum, foi comunicado o chamado para publicação do primeiro número temático dedicado ao assunto, na Revista de Arqueologia da SAB, sob a coordenação da professora Loredana Ribeiro (2017), que julgamos ser um importante marco para o avanço das pesquisas sobre o tema no Brasil.

Essa edição contou com a apresentação do trabalho de realidade virtual realizado pelo Laboratório de Arqueologia Romana Provincial (Larp/MAE-USP) em conjunto com o Centro Interdisciplinar de Tecnologia Interativas (CITI-USP). Participantes puderam experienciar, através da realidade aumentada, a reconstrução Digital do Sarcófago do Rei Ahiram de Biblos, produzido a partir de uma réplica presente na USP desde 1966. Além disso, o Larp/MAE-USP apresentou réplicas de peças arqueológicas impressas em 3D. A exposição fotográfica teve como tema "Olhares trocados: uma visão sobre expedições arqueológicas de brasileiros(as) no exterior e de estrangeiros(as) no Brasil". Para dar continuidade à parceria com a Maia, foi proposta uma sessão de apresentação de trabalhos audiovisuais, além das sessões de comunicação oral e de pôsteres. Foi a primeira edição com a possibilidade de graduandes apresentarem comunicações orais, mas o modelo de "mesa redonda" testado anteriormente não foi mantido.

Devido à demora da publicação dos Anais da edição anterior, a comissão organizadora não propôs a publicação de artigos para essa edição.

Por fim, a VI SIA foi realizada de 20 a 24 de maio de 2019 nos novos auditórios da FFLCH-USP. Foi a edição que contou com o maior número de participantes até o momento (391 pessoas envolvidas) e a contar com financiamento aberto para a vinda de estudantes que não tivessem condições socioeconômicas, por meio da chamada pública "Adote um estudante".

A comissão organizadora foi composta por Aline Oliveira, Anderson Tognoli, Bruno Barreto, Daniel Fidalgo, Emerson Nobre, Igor
Rodrigues, Kelly Brandão, Mauricio André da Silva, Michelle Pedroso, Rafael Lopes, Renan Rasteiro, Renata Estevam da Silva, Renato Saad e Thiago Kater. A professora coordenadora dessa edição foi Elaine Farias Veloso Hirata, contando ainda com sete colaboradories. Para ampliar a construção da Semana, um questionário prévio foi elaborado e encaminhado para todo o corpo discente do MAE e para participantes das edições anteriores, para que pudessem indicar quais temas gostariam de ver debatidos na SIA. Apareceram como destaque discussões de gênero, sexualidade e comunidades tradicionais, como indígenas e quilombolas. Dessa forma, se amplia a construção do evento para além dos interesses da comissão organizadora e de discentes do MAE. Assim, foram convidados onze palestrantes nacionais e seis palestrantes estrangeiros, com destaque para o fato de que essa foi a primeira edição a contar com a participação de representantes (já envolvides com trabalhos arqueológicos ou inserides na academia) de cada uma das comunidades-perspectivas abordadas nas mesas redondas temáticas.

Foram realizadas cinco mesas temáticas: Desafios atuais das pesquisas arqueológicas; Arqueologia da repressão e resistência: materialidade e patrimônio em áreas de conflito; Por que uma Arqueologia Queer?; Arqueologias Quilombolas; e Arqueologias Indígenas (Quadro 6). Além dessas mesas, a VI SIA contou com um fórum sobre o desmonte da ciência e as perspectivas futuras da Arqueologia, com o lançamento do jogo "Sambaqui: Uma História Antes do Brasil”, desenvolvido pelo Grupo Arqueologia Interativa e Simulações Gráficas (ARISE, MAE-USP) e pelo Grupo de Pesquisa em Educação Patrimonial e Arqueologia da Universidade do Sul de Santa Catarina (Grupep, Unisul), e com a abertura de espaço para venda de artesanato produzido por comunidades indígenas e réplicas de cerâmicas tapajônicas. Como palestra de encerramento, tivemos a fala de Chip Cowell que retomou as discussões sobre o papel de arqueólogue, preservação de patrimônio e contexto nacional, especialmente após o incêndio do Museu Nacional em setembro de 2018 
Surgimento e consolidação da Semana Internacional de Arqueologia Discentes MAE-USP: uma reflexão R. Museu Arq. Etn., 34: 1-25, 2020.

\begin{tabular}{|c|c|c|}
\hline \multicolumn{3}{|c|}{ V Semana Internacional de Arqueologia Discentes MAE-USP } \\
\hline Palestrante & Tema & Mesa \\
\hline $\begin{array}{l}\text { Whitney Battle-Baptiste } \\
\text { (UMass Amherst, Estados Unidos) }\end{array}$ & $\begin{array}{l}\text { Moving mountains and liberating dialogues: my journey towards } \\
\text { creating a Black Feminist Archaeology }\end{array}$ & $\begin{array}{l}\text { Palestra de } \\
\text { abertura }\end{array}$ \\
\hline $\begin{array}{l}\text { Camila Gianotti } \\
\text { (Universidad de la } \\
\text { República, Uruguai) }\end{array}$ & $\begin{array}{l}\text { El paisaje monumental de las tierras bajas de Uruguay: el rol de } \\
\text { la arquitectura en tierra en la construcción del territorio }\end{array}$ & \multirow{3}{*}{$\begin{array}{l}\text { Arqueologia } \\
\text { da paisagem }\end{array}$} \\
\hline $\begin{array}{l}\text { Julio Cezar Rubin de Rubin } \\
\text { (Pontifícia Universidade Católica de } \\
\text { Goiás - PUC-GO) }\end{array}$ & Reflexões sobre paisagem e Arqueologia & \\
\hline $\begin{array}{l}\text { Manuel Arroyo-Kalin } \\
\text { (University College London, Inglaterra) }\end{array}$ & $\begin{array}{l}\text { Intencionalidade, demografia e legados antrópicos nas } \\
\text { paisagens da Amazônia pré-colonial }\end{array}$ & \\
\hline \begin{tabular}{|l|} 
Helena Pinto Lima \\
(Moviment Picture Experts \\
Group - MPEG)
\end{tabular} & $\begin{array}{l}\text { Patrimônio, souvenir ou negócio? A circulação ilegal de } \\
\text { bens arqueológicos da Amazônia }\end{array}$ & \multirow{3}{*}{$\begin{array}{l}\text { Comércio } \\
\text { ilegal de bens } \\
\text { arqueológicos }\end{array}$} \\
\hline $\begin{array}{l}\text { Marcia Arcuri } \\
\text { (Universidade Federal de } \\
\text { Ouro Preto e MAE-USP) }\end{array}$ & $\begin{array}{l}\text { Direito internacional do patrimônio cultural - do tráfico } \\
\text { ilícito de bens culturais arqueológicos }\end{array}$ & \\
\hline Anauene Dias Soares & $\begin{array}{l}\text { Direito internacional do patrimônio cultural - do tráfico } \\
\text { ilícito de bens culturais arqueológicos }\end{array}$ & \\
\hline $\begin{array}{l}\text { Camila Azevedo de Moraes Wichers } \\
\text { (UFG) }\end{array}$ & $\begin{array}{l}\text { Prática arqueológica e a construção de coleções e narrati- } \\
\text { vas: patrimonialização, disputa e ressignificação a partir } \\
\text { do olhar museológico }\end{array}$ & \multirow{3}{*}{$\begin{array}{l}\text { Gestão de } \\
\text { acervos } \\
\text { arqueológicos }\end{array}$} \\
\hline $\begin{array}{l}\text { Fernanda Tocchetto } \\
\text { (Museu de Porto Alegre } \\
\text { Joaquim Felizardo) } \\
\end{array}$ & ( & \\
\hline $\begin{array}{l}\text { Silvia Cunha Lima } \\
\text { (MAE-USP) }\end{array}$ & $\begin{array}{l}\text { Conservação de acervos arqueológicos: as recomendações } \\
\text { da Portaria } 196\end{array}$ & \\
\hline $\begin{array}{l}\text { Artur Barcelos } \\
\text { (Universidade Federal do } \\
\text { Rio Grande - FURG) } \\
\end{array}$ & $\begin{array}{l}\text { Para além das ruínas: a Arqueologia, o patrimônio e as } \\
\text { missões jesuíticas no Sul do Brasil }\end{array}$ & \multirow{3}{*}{$\begin{array}{l}\text { Arqueologia } \\
\text { Histórica }\end{array}$} \\
\hline $\begin{array}{l}\text { Fernanda Codevilla Soares } \\
\text { (UFMG) }\end{array}$ & $\begin{array}{l}\text { Arqueologia abaixo de zero: estudo da ocupação humana } \\
\text { da Antártica }\end{array}$ & \\
\hline $\begin{array}{l}\text { Diogo Costa } \\
\text { (UFPA) }\end{array}$ & $\begin{array}{l}\text { Arqueologia histórica na Amazônia: o projeto sítio-escola } \\
\text { Engenho do Murutucu }\end{array}$ & \\
\hline \begin{tabular}{|l|} 
Manuel Gándara \\
(Escuela Nacional de Conservación, \\
Restauración y Museografía del \\
Instituto Nacional de Antropología e \\
História - ENCRyM-INAH, México) \\
\end{tabular} & $\begin{array}{l}\text { La articulación entre teoría arqueológica y divulgación del patri- } \\
\text { monio: reflexiones en torno al caso de Xochicalco, México }\end{array}$ & $\begin{array}{l}\text { Palestra de } \\
\text { encerramento }\end{array}$ \\
\hline
\end{tabular}

Quadro 5: Palestrantes e temas da V Semana Internacional de Arqueologia Discentes MAE-USP. 


\begin{tabular}{|c|c|c|}
\hline \multicolumn{3}{|c|}{ VI Semana Internacional de Arqueologia Discentes MAE-USP } \\
\hline Palestrante & Tema & Mesa \\
\hline $\begin{array}{l}\text { Antonio Carlos Souza Lima } \\
\text { (UFRJ/Capes) }\end{array}$ & \multirow{4}{*}{ - } & \multirow{4}{*}{$\begin{array}{l}\text { Desafios atuais } \\
\text { das pesquisas } \\
\text { arqueológicas }\end{array}$} \\
\hline $\begin{array}{l}\text { Márcia Bezerra } \\
\text { (UFPA/Capes) }\end{array}$ & & \\
\hline $\begin{array}{l}\text { Eduardo Neves } \\
\text { (MAE-USP) }\end{array}$ & & \\
\hline $\begin{array}{l}\text { Flávio Franco } \\
\text { (Associação Nacional de } \\
\text { Pós-Graduandos - ANPG) }\end{array}$ & & \\
\hline $\begin{array}{l}\text { Nicole Fuenzalida } \\
\text { (Universidad de Chile) }\end{array}$ & $\begin{array}{l}\text { Elementos para pensar (o impensável): tortura elétrica } \\
\text { como paradoxo }\end{array}$ & \multirow{3}{*}{$\begin{array}{l}\text { Arqueologia da } \\
\text { repressão e } \\
\text { resistência: } \\
\text { materialidade e } \\
\text { patrimônio em } \\
\text { áreas de conflito } \\
\end{array}$} \\
\hline $\begin{array}{l}\text { Andres Zarankin } \\
\text { (UFMG) }\end{array}$ & O ovo da serpente & \\
\hline Crimeia Alice Schmidt de Almeida & Maternidade e a materialidade na repressão & \\
\hline $\begin{array}{l}\text { Maria Fernanda Ugalde } \\
\text { (Pontifícia Universidade } \\
\text { Católica do Equador) }\end{array}$ & $\begin{array}{l}\text { Gênero e poder há } 2.500 \text { anos: uma releitura Queer } \\
\text { da iconografia do Equador Pré-Hispânico }\end{array}$ & \multirow{3}{*}{$\begin{array}{l}\text { Por que uma } \\
\text { Arqueologia Queer? }\end{array}$} \\
\hline $\begin{array}{l}\text { Hugo Benavides } \\
\text { (Fordham University) }\end{array}$ & $\begin{array}{l}\text { Por que uma Arqueologia Queer? A política de sexo e } \\
\text { gênero na história do presente em desaparecimento }\end{array}$ & \\
\hline $\begin{array}{l}\text { Gabby Hartemann } \\
\text { (UFMG) }\end{array}$ & Silêncio, o lixo está falando. & \\
\hline $\begin{array}{l}\text { Theresa Singleton } \\
\text { (Universidade de Siracusa, } \\
\text { Estados Unidos) }\end{array}$ & Archaeology of marronage in the Caribbean Antilles & \multirow{3}{*}{$\begin{array}{l}\text { Arqueologia } \\
\text { quilombola }\end{array}$} \\
\hline $\begin{array}{l}\text { Irislane Pereira } \\
\text { (Universidade Federal do } \\
\text { Amapá - Unifap) }\end{array}$ & $\begin{array}{l}\text { Arqueologias Quilombolas? Refletindo entraves, } \\
\text { desafios e possibilidades a partir de uma } \\
\text { perspectiva afrocentrada }\end{array}$ & \\
\hline $\begin{array}{l}\text { Silvio Campos } \\
\text { (Conselheiro tutelar da Bahia) }\end{array}$ & Arqueologia e a comunidade do Galeão/BA & \\
\hline $\begin{array}{l}\text { Patricia Ayala } \\
\text { (Abbe Museum, Estados Unidos) }\end{array}$ & Arqueologias indigenas: una mirada desde el Sur & \multirow{3}{*}{$\begin{array}{l}\text { Arqueologias } \\
\text { indígenas }\end{array}$} \\
\hline $\begin{array}{l}\text { Camila P. Jácome } \\
\text { (UFOPA) }\end{array}$ & $\begin{array}{l}\text { Do campo à academia, algumas reflexões sobre } \\
\text { arqueologias indigenas }\end{array}$ & \\
\hline $\begin{array}{l}\text { Jaime Xamen Wai Wai } \\
\text { (UFMG) }\end{array}$ & $\begin{array}{l}\text { Arqueologia Indigena dos povos do Rio Mapuera, } \\
\text { Oriximiná-PA. Experiência de Arqueologia WaiWai. }\end{array}$ & \\
\hline $\begin{array}{l}\text { Chip Colwell } \\
\text { (Museu da Natureza e Ciência de } \\
\text { Denver, Estados Unidos) }\end{array}$ & Arqueologia colaborativa não é o fim & $\begin{array}{l}\text { Palestra de } \\
\text { encerramento }\end{array}$ \\
\hline
\end{tabular}

Quadro 6: Palestrantes e temas da VI Semana Internacional de Arqueologia Discentes MAE-USP.

\section{Um balanço do histórico}

Após seis edições, as motivações para realizar esse evento mantêm-se, em parte, as mesmas: compartilhar temas transversais de pesquisas e conhecer a temática dos trabalhos de demais colegas do Museu e de outras instituições, promover o diálogo entre 
estudantes e pesquisadories. Com a proporção que as edições anteriores foram tomando, participar da comissão organizadora passou a deixar ainda mais clara a necessidade de espaços discentes para debates e trocas, que muitas vezes não ocorrem nos grandes eventos nacionais e regionais.

Em todas as edições observa-se um viés político e militante da comissão organizadora ao querer manter o evento amplo e acessível aos diversos públicos, cada vez abrindo mais as categorias de participação e as temáticas abordadas. Os temas escolhidos ao longo do tempo refletem motivações do corpo estudantil durante a organização e as agendas do contexto profissional no momento, que não é descolado da produção acadêmica cotidiana. Outro aspecto relevante da SIA é a escolha de alguns temas pouco abordados por pesquisas no MAE. Essa busca evidencia o desejo de estudantes para ampliação e alargamento das áreas de pesquisa do Museu, especialmente a fim de acompanhar as transformações da Arqueologia no mundo contemporâneo.

Diversos produtos elaborados durante as edições se tornaram material permanente de acesso aberto e memória dos eventos, como websites, páginas de divulgação em redes sociais, materiais de divulgação, como panfletos e cartazes, cadernos de resumo, exposições, filmagens ${ }^{7}$ das palestras e mesas redondas, transmissões ao vivo, publicações de anais e dossiês. Isso demonstra que a SIA não se restringe apenas ao momento em que está acontecendo, mas que permite a continuidade do que é discutido ao longo dela.

Durante as seis SIAs muitos tipos de atividades foram experimentados, alguns que atravessavam o próprio calendário do evento, como cursos realizados com palestrantes que ocorreram antes ou depois do evento. Exposições fotográficas, mostras de filmes, apresentações de materiais didáticos desenvolvidos por discentes do programa e

7 As filmagens acontecem em parceria com o setor do audiovisual do MAE, que está trabalhando no tratamento dos vídeos, inclusão de legendas e créditos para posterior divulgação. aplicativos de realidade virtual são algumas atividades que estiveram presentes em pelo menos uma edição da SIA.

Se na IV SIA, em 2015, houve um grande debate sobre busca de recursos financeiros para o desenvolvimento dos trabalhos, como avançar as pesquisas arqueológicas e o trabalho na arqueologia de contratos, em 2019 foi necessário refletir como a ciência no Brasil enfrentará os duros ataques atuais e como fomentar espaço para que as vozes, até então invisibilizadas nestes espaços, fossem expressas. Aliás, foi necessário ir além e garantir, por contribuições coletivas, a presença de estudantes de origem quilombola, indígena e pessoas trans, que se identificaram imediatamente com os temas propostos.

Com o crescimento do evento, a partir da III SIA as atividades foram realizadas fora do espaço físico do MAE. Fato que promoveu a interação dos estudantes com a USP como um todo, contudo, tendo o MAE grande visibilidade em toda a comunidade arqueológica, edições III, IV, V e VI da SIA também promoveram atividades no museu, como visitas orientadas a reservas técnicas e exposições em cartaz.

Não podemos deixar de falar das festas de confraternização ao final da SIA que ocorrem desde a primeira edição para aproximar ainda mais estudantes, docentes, servidories técniques, convidades e participantes. Assim como os intervalos para "coffee break", esse espaço vem se consolidando como um momento informal, e muitas vezes lúdico, que permite tirar dúvidas, apresentar outras perspectivas e até mesmo a troca de contatos e estabelecimento de novas parcerias.

De acordo com os questionários aplicados para organizadories das diferentes edições, os pontos positivos mais apontados foram: integração de alunes de diferentes laboratórios de pesquisa do MAE-USP, ampliação da interlocução fora de seus grupos de pesquisa, contato direto com docentes, experiência com burocracias e logísticas da organização de um evento. Já erros burocráticos, atraso das agências financiadoras, organização das publicações, 
Kelly Brandão, Aline Oliveira, Meliam Gaspar, Mauricio André da Silva, Renato Saad Panunzio, Renata Estevam, Emerson Nobre e Elaine Farias Veloso Hirata

dificuldade em balancear as opiniões e engajamento foram considerados pontos negativos.

A comissão organizadora da I SA salienta como é gratificante ver a importância desse evento atualmente responsável pela formação de tantes arqueólogues no Brasil, e ressalta a importância de manter o protagonismo de estudantes na organização desse tipo de encontro. Segundo a avaliação de uma das organizadoras, que era doutoranda na época, o crescimento da Semana é positivo, pois ele tomou grande proporção e relevância no cenário nacional da Arqueologia, sendo um evento que traz pesquisadories do Brasil e do exterior, mas que continua aberto a estudantes.

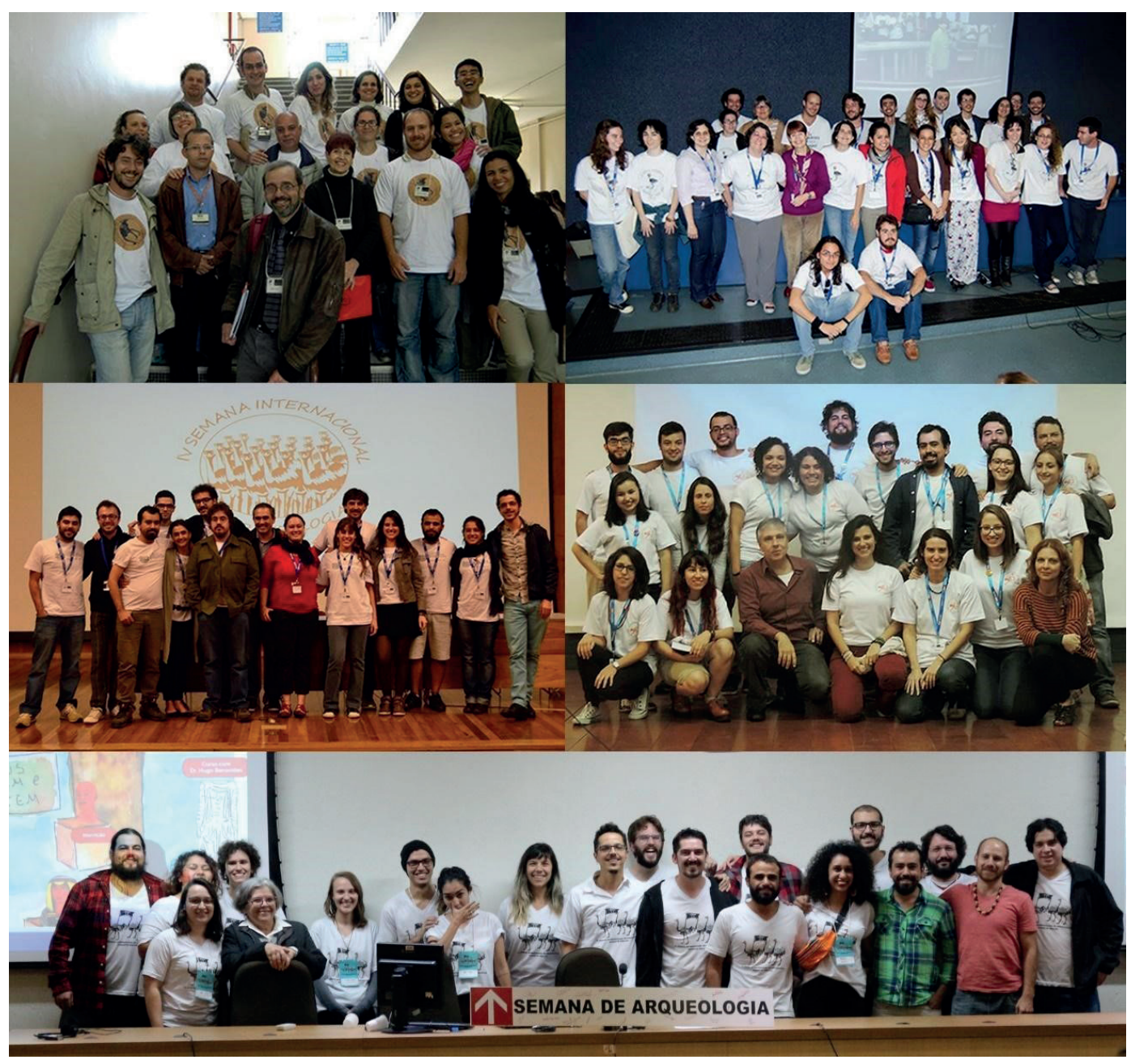

Fig. 1. Imagens das equipes organizadoras da SIA em cinco edições.

Fonte: Acervo MAE-USP. 


\section{Os espaços destinados à comunicação oral}

As sessões de comunicação oral e de pôsteres são o coração da SIA, pois são os lugares onde participantes compartilham suas pesquisas e dialogam entre si.

Até a III edição era possível apresentar mais de um trabalho por categoria, porém, devido à grande quantidade de inscrições, estabeleceu-se apenas uma apresentação por autoria, para garantir a participação de todes. Até o momento, nenhuma inscrição foi negada em qualquer das edições. A equipe de inscrições trabalha para que esse seja um espaço seguro, onde estudantes se sintam à vontade para participar, e apenas sugere alterações e melhorias nos resumos enviados.

A SIA sempre estimulou a apresentação oral de estudantes da pós-graduação, porém colegas da graduação sempre foram bem vindes e estimulades a participarem pela apresentação de pôsteres, que, inclusive, são premiados ao final do evento. Na V SIA, foi aberto o espaço de comunicação oral também para graduandes. A princípio, essa opção estaria condicionada à disponibilidade de espaço, o que até o momento não foi problema.

Estudantes que apresentaram comunicações puderam, em quase todas as edições, ter seus artigos completos publicados nos anais da SIA pela Revista do MAE. Além de ser um registro do evento, esse espaço incentiva a publicação das pesquisas, ou parte delas, por estudantes de pós-graduação, um exercício fundamental durante a vida acadêmica.

Ao longo de todas as edições houve o esforço para que o evento não ficasse dividido em ilhas de conhecimento. Desde o princípio, a ideia foi colocar pessoas que trabalhavam com diferentes áreas para dialogar, norteadas por um eixo comum (mas nem sempre óbvio) às suas pesquisas. $\mathrm{O}$ que causou estranhamentos em algumas pessoas e foi surpreendente para outras. $\mathrm{O}$ interesse de criar um diálogo que de fato agregasse pesquisas em diferentes áreas criou um debate interno que perpassa todas as edições, ensinando como conduzir as sessões de comunicação de modo a procurar a fluidez de ideias e o diálogo entre diferentes áreas da Arqueologia.

Algumas ferramentas foram testadas, como a utilização de temas de áreas de concentração mais abrangentes nos quais es própries alunes classificavam seus trabalhos, ou solicitar palavras chaves para conduzir essa classificação. O esforço da comissão organizadora sempre foi o de não alocar trabalhos de um mesmo laboratório ou grupo de pesquisa numa única sessão. Por exemplo, ao invés de usar o tema "Amazônia", um tema transversal e integrador foi escolhido: "cerâmica". Assim, profissionais e pesquisadories que trabalham com cerâmica em diferentes contextos (como Amazônia ou Mediterrâneo), aparentemente estranhos um ao outro, puderam dialogar e comparar suas perspectivas. Essa maneira de construir sessões de comunicação é bastante complexa e resulta em muito trabalho da organização, leituras atentas dos resumos e flexibilidade, de coordenadories de sessões.

Ressaltamos que o objetivo principal das sessões de comunicação é o diálogo. Quando trabalhos de linhas de pesquisas diferentes são abordados conjuntamente em torno de um eixo central, é possível enxergar quais são as questões em comum de áreas que de longe parecem tão distintas. Nesses espaços em que se fala fora da "zona de conforto" é possível exercitar a escuta, a construção de novos diálogos e a evitar o isolamento de subáreas da disciplina. Ao final das edições, isso fez com que grande parte do público definisse o evento com os termos "diversidade" e "socialização do conhecimento".

\section{Identidade visual}

Na primeira edição do encontro, a identidade visual foi estruturada e trabalhada em cima de uma figura serpentiforme, inspirada na iconografia da cerâmica tapajônica. No entanto, a partir da segunda edição foi introduzida a figura do avestruz, que se consolidou como ícone da SIA e a cada edição é repensado para dialogar com as discussões dos temas trazidos por cada grupo de organizadories. É importante ressaltar que todos 
os trabalhos de identidade visual também foram realizados por discentes do MAE-USP.

Durante a segunda edição, a escolha do avestruz foi pensada para refletir, de maneira metafórica, algumas discussões e reflexões realizadas na Arqueologia. Primeiramente, pensou-se em um animal que possui a característica de cavar e fazer buracos na terra, a exemplo de um tatu. Entretanto, a figura do avestruz pareceu mais apropriada devido ao seu caráter simbólico, que no imaginário popular enterra a sua cabeça em buracos, assim como arqueólogues. Desse modo, o avestruz foi retratado com a cabeça dentro de um buraco na terra, enquanto o caderno de resumos quadriculado fazia referência às escavações arqueológicas.

Na III SIA, o avestruz foi retratado de pé sobre uma área demarcada por quadrículas, mas dessa vez com a cabeça fora do buraco na terra, de onde havia tirado um vaso de cerâmica que cobria seu rosto. A identidade visual do site e caderno de resumos retomou o tema da escavação, com quadrículas e ferramentas de trabalho de campo. No logotipo da IV SIA, o tradicional avestruz se converteu em uma ema, animal nativo, que mostra seu rosto para se juntar a seus pares e repensar os rumos da disciplina. As emas olham à frente, de modo a expressar que é fundamental à Arqueologia ampliar seu panorama para que suas discussões, reflexões, bem como o seu papel social, sejam ampliados. É também por isso que o site e caderno de resumos foram estilizados por um rascunho de mapa, com ícones que representavam diferentes áreas de estudo

(de temática indígena, africana, mediterrânica, entre outras). Para ficar claro que é um evento organizado por discentes, o nome passou a constar no logotipo como Semana Internacional de Arqueologia Discentes MAE-USP.

$\mathrm{Na}$ quinta edição, a figura do avestruz foi trabalhada ao estilo de uma pintura rupestre, de modo a dialogar com algumas discussões e reflexões relativas à fruição e manejo do patrimônio arqueológico. A preocupação com o destino do Parque Nacional da Serra da Capivara, entre outros patrimônios arqueológicos no país, que estavam ameaçados com a crescente falta de verbas e o risco de retirada de políticas públicas para sua proteção. Tanto o website como o caderno de resumos apresentaram a figura do avestruz (ou da ema) em diferentes estilos de pintura rupestre.

Para a VI SIA, o logotipo combinou duas emas com um avestruz que trazia consigo uma bandeira com o símbolo da luta em Arqueologia, como em uma manifestação. A referência por trás desse design foi a pintura "A Liberdade guiando o povo", de Eugène Delacroix. O caráter colonialista da pintura foi esvaziado, de modo a atribuir um valor mais próximo à agenda do evento. A manifestação das emas e do avestruz foi em prol de uma Arqueologia mais política, mais engajada e mais heterogênea no que diz respeito às diferentes identidades e vozes. Concomitantemente, essa luta em Arqueologia também pretendia chamar a atenção e refletir sobre o desmantelamento da ciência e o sucateamento dos museus universitários no país, materializado no fatídico incêndio que destruiu o Museu Nacional (MN) e parte significativa do seu acervo.

A memória do $\mathrm{MN}$ foi homenageada no caderno de resumos e nos meios de divulgação do evento por meio de um desenho em aquarela que mostrava uma sala com vários itens emblemáticos do Museu expostos (crânio da Luzia, cerâmicas marajoara, sarcófago de Sha-Amun-en-su, entre outros), com destaque à frase "Museus existem e resistem".

As modificações no logotipo do evento podem ser compreendidas como transformações dos anseios de alunes do programa de Arqueologia e debates da SIA. Outro ponto é que, durante a organização da IV SIA, a imagem do avestruz (ou da ema) enquanto ícone do evento já estava tão consolidada que foram introduzidas duas mascotes de pelúcia para colaborar na divulgação: Frida e Ema. Durante o período que antecede o evento, as duas circulam e são fotografadas pelos laboratórios do MAE para integrar discentes e o Museu, e fazem parte de campanhas de divulgação pelas redes sociais. Frida e Ema tornaram-se tão queridas e emblemáticas que, quando desapareceram, durante a VI SIA; uma campanha para seu retorno nas redes sociais contou com a colaboração de muitas pessoas dispostas a vê-las de volta ao lar e, em poucos dias elas reapareceram. 

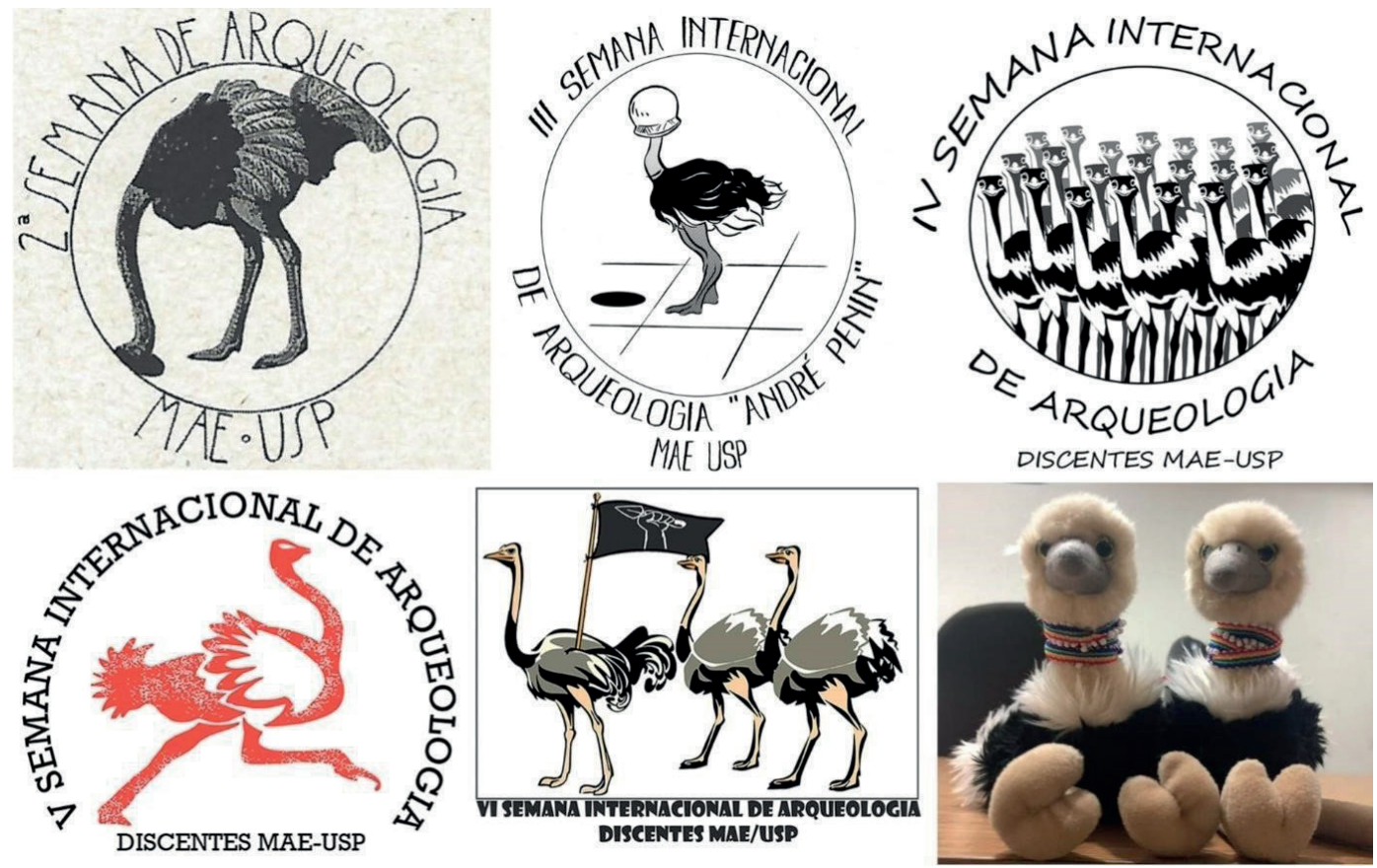

Fig. 2. Logotipos dos eventos, mostrando a evolução do avestruz.

Apoio financeiro e institucional

A realização das diferentes edições da SIA teve, sem dúvidas, grande esforço de organização do corpo estudantil, porém para que elas fossem realizadas da forma como foram idealizadas foi necessário apoio institucional e de ordem financeira.

Ao longo dos anos, o MAE-USP, por meio da sua diretoria e professories, apoiou e incentivou a organização de alunes para a realização do evento. Algumas vezes esse apoio também foi financeiro, além de constante disponibilização do quadro funcional para auxílio prático antes, durante e depois do encontro. É papel fundamental das instituições, através dos programas de pós-graduação e graduação, incentivar a organização de eventos científicos pelo corpo discente, o que permite ao corpo estudantil o exercício da autonomia, do planejamento, da criação e principalmente do trabalho coletivo e da resolução de crises.

O valor da inscrição sempre foi pensado para que não fosse um empecilho na participação de estudantes, porém, dificilmente é possível organizar um evento de grandes proporções sem recursos. Dessa forma, o primeiro passo da organização, em todas as edições, foi elaborar projetos para captação de recursos de agências de fomento, como a Coordenação de Aperfeiçoamento de Pessoal de Nível Superior (Capes), o Conselho Nacional de Desenvolvimento Científico e Tecnológico (CNPQ) e a Fundação de Amparo à Pesquisa do Estado de São Paulo (Fapesp). Cada edição teve diferentes orçamentos disponíveis (Quadro 7). É importante ressaltar que com a periodicidade da SIA e a crescente qualidade dos relatórios finais, as verbas das agências se consolidaram.

O financiamento das agências de fomento possibilitou trazer nomes importantes da comunidade científica internacional e nacional sem transferir esse custo para participantes, ampliando o acesso de estudantes em discussões atuais da academia e colaborando na reflexão de sua própria pesquisa.

Além das agências de fomento, é fundamental pontuar a participação da 
Universidade de São Paulo através das prós-reitorias de Pós-graduação, de Extensão e Cultura, e de Pesquisa no complemento do financiamento de passagens e diárias para palestrantes. Com isso foi possível também a realização de pelo menos três cursos de extensão universitária ${ }^{8}$, que possibilitaram o aprofundamento de diversos temas e a participação de estudantes de outros cursos da universidade. Outro apoio fundamental da universidade foi a redução de preços do restaurante universitário e disponibilização de alojamento para participantes.

Em 2015, na quarta edição, houve um contratempo na disponibilização de recursos das agências de fomento: somente um terço do total solicitado foi recebido. Isso afetou a programação e o planejamento de diferentes maneiras, mas com o apoio do MAE e da USP, foi possivel manter o evento como planejado. Com o congelamento e a diminuição em investimento na área científica realizados pelo governo atual, a realização de eventos desse tipo passa a correr riscos. Quando há dificuldade em conseguir bolsas de estudos para o sustento básico do indivíduo, a organização e participação em eventos ficam restritas a um número cada vez menor de estudantes e cientistas. Mesmo nesse cenário, a SIA pretende continuar com seu espaço de promoção do conhecimento e lutar para que possa ocorrer em 2021.

Até o momento, o financiamento recebido foi suficiente para que a Semana ocorresse mais ou menos próxima de seu planejamento inicial. Contudo, muitos estudantes já deixaram de participar devido a cortes realizados pelas agências de fomento em suas instituições de origem, que antes permitiam sua participação em eventos científicos por meio de auxílios e bolsas de estudo. É por isso que, durante a última edição, a comissão organizadora foi consultada por diversos estudantes

8 III SIA: Prof. Dr. Patrick Le Roux, "Os domínios portugueses no alto império romano: sociedades e culturas", 15 a 18 de abril de 2013; V SIA: Prof. Dr. Manuel Gándara Vazquez, "La divulgación del patrimonio arqueológico: una aproximación desde México”, de 15 a 17 de maio de 2017; VI SIA: Prof. Dr. Oswaldo Hugo Benavides, "An Archaeology of the Global South: Racing Sex to Identities in the Latin American Past”, 15 a 17 de maio de 2019. sobre a possibilidade de ajuda de custo para transporte, hospedagem e alimentação. Isso partiu principalmente de estudantes que se reconheceram nas discussões propostas pelo evento. Apesar dos incentivos de baixo custo da USP, conforme a região de origem de estudante, esses valores ainda eram altos. Dessa forma, foi elaborado um formulário para entender as necessidades des participantes, que foi divulgado para todos os cursos de graduação e pós-graduação de Arqueologia, além das mídias sociais. Em consequência, foi organizada uma campanha de arrecadação online $e^{9}$ que possibilitou a vinda de nove estudantes de origem indígena, quilombola e de pessoas trans.

O Quadro 7 demonstra que os valores de financiamento aumentaram progressivamente ao longo dos anos, contudo, mesmo quando os valores são similares (financiamento total/participante), eles não contam com a inflação. Os valores informados referem-se ao total fornecido por todas as agências de fomento somadas, que é recebido em nome de professories coordenadories da edição, mas não incluem o valor das taxas de inscrição. A maior parte desses orçamentos é destinada para a compra de passagens e diárias de convidades, mas outros gastos (como serviços de tradução simultânea e "coffee break") são os que mais consomem do montante fornecido. Tradução simultânea é um gasto importante, pois demonstra que manter um encontro que defende a inclusão de temáticas e de público necessita que todes sejam capazes de se compreender, independentemente do idioma.

Agências de fomento funcionam com alíneas específicas de gastos, que associam os valores com gastos pré-determinados por eles. Isso dificulta especialmente o pagamento de pequenos gastos, como elaboração de kits, crachás e combustível para buscar convidades em aeroportos, além de outras demandas que não foram previstas inicialmente. Por isso, os valores arrecadados com taxas de inscrição, que entram diretamente em uma conta bancária da SIA, são tão importantes para a organização do evento.

9 Disponível em: 〈http://vaka.me/506726>. Acesso em: 24/07/2020 
Surgimento e consolidação da Semana Internacional de Arqueologia Discentes MAE-USP: uma reflexão R. Museu Arq. Etn., 34: 1-25, 2020.

\begin{tabular}{|c|c|c|c|l|}
\hline Edição & Participantes & Convidados & Financiamento & \multicolumn{1}{|c|}{ Agências } \\
\hline I SA & 120 & 10 & - & $\begin{array}{l}\text { Fapesp, Pró-reitoria de Pós-graduação e Pró-reitoria de } \\
\text { Pesquisa da USP, Itaú e Santander }\end{array}$ \\
\hline II SA & 244 & 11 & $\mathrm{R} \$ 7.940,00$ & $\begin{array}{l}\text { Capes, MAE, Pró- reitoria de Pós-graduação } \\
\text { da USP, Petrobrás }\end{array}$ \\
\hline III SIA & 280 & 16 & $\mathrm{R} \$ 77.801,54$ & $\begin{array}{l}\text { Capes, CNPq, Fapesp, Pró-reitoria de Pesquisa da USP, } \\
\text { Beta Analytics }\end{array}$ \\
\hline IV SIA & 348 & 11 & $\mathrm{R} \$ 55.486,00$ & $\begin{array}{l}\text { Capes, CNPq, Fapesp, Pró-reitoria de Pesquisa da USP, } \\
\text { Beta Analytics }\end{array}$ \\
\hline V SIA & 284 & 14 & $\mathrm{R} \$ 64.810,00$ & $\begin{array}{l}\text { Capes, CNPq, Fapesp, Pró-reitoria Cultura e Extensão } \\
\text { da USP, Consulado do México, Beta Analytics }\end{array}$ \\
\hline VI SIA & 391 & 17 & $\mathrm{R} \$ 77.640,00$ & Capes, Fapesp, Pró-reitoria de Pós-graduação da USP \\
\hline
\end{tabular}

Quadro 7. Edições do evento com número de participantes inscritos, palestrantes convidados, valor total do financiamento e agências de fomento.

\section{Organizadories, convidades e público}

Uma preocupação recente na Arqueologia no Brasil é entender a diversidade identitária de profissionais e estudantes que atuam no país ${ }^{10}$. Inicialmente focada na discussão sobre gênero, principalmente para pensar a participação de mulheres e homens na área, outras preocupações têm sido incorporadas apesar de ainda não terem sido estudadas sistematicamente (como gêneros não binários, orientação sexual, identidades étnico-raciais, e região de formação) ${ }^{11}$. A exemplo da análise feita por Priscilla Ulguim (2019) para o XX Congresso da Sociedade de Arqueologia Brasileira (SAB), fizemos um exercício para refletir sobre alguns aspectos da diversidade de participantes nas edições das SIAs.

Ao analisar a programação oficial nos cadernos de resumo e listas de inscritos em cada edição, é possível discutir alguns dados. O primeiro é a participação de homens e mulheres (de acordo com uma atribuição do senso comum do que são nomes masculinos e femininos). O segundo é a região de participantes, pela instituição a qual

10 Para saber mais, vide Ribeiro (2017).

11 Sobre Arqueologia Queer, ver Pouget e Carvalho (2019). Ver também Negrarqueo - Rede de Arqueologia Negra. Disponível em: 〈https://bit.ly/32RIS8Q>. Acesso em 24/07/2020. estão vinculades. Nos dois casos, podemos fazer algumas observações de cunho qualitativo, já que conhecemos grande parte des participantes e sabemos de pessoas que se identificaram de maneira diferente durante o evento ${ }^{12}$.

Consideramos, então, alguns recortes: contabilizamos somente o primeiro nome de autoria, com repetição (se apresentou dois trabalhos, ou se participou em mais de uma categoria); a região considerada é a da instituição de autores, como consta no caderno de resumos; não consideramos mudanças de última hora na programação e nem pessoas que não compareceram. Dividimos a análise por categorias: organizadories, palestrantes, coordenadories de mesas, apresentadories de comunicação e pôster. Palestrantes e coordenadories são convidados pela organização, o que representa a escolha de pessoas para dialogar determinados temas. Já organizadories e apresentadories participam voluntariamente, o que pode refletir a iniciativa (ou incentivo) de pessoas para participar e também a própria diversidade do programa de pós no MAE e em outras instituições. Ouvintes não foram considerados nessa análise por falta de dados consistentes para todas as edições.

12 Existem outros eixos de análise possíveis de serem feitos por meio dessa documentação oficial, mas que não foram feitos para este artigo por falta de tempo: áreas temáticas de pesquisa de apresentadores; agências financiadoras das pesquisas e relações com coautories. 
Como é possível observar na Fig. 3, a participação total de mulheres é maior que a de homens em todas as edições, com exceção da primeira (mas ainda assim é bastante equilibrada). A relação entre mulheres e homens convidades para palestrar varia de uma edição para outra, ora de maneira mais equilibrada (I, II, VI), mais homens (III, IV) ou mais mulheres (V). Um destaque é para a participação de uma pessoa trans não binária como palestrante na VI SIA. Já para coordenadores de mesas redondas e sessões de comunicação, a partir da III edição foram convidadas mais mulheres que homens. Normalmente, coordenadories são professories do MAE (onde a maioria é feminina) ou alunes e ex-alunes presentes no evento.

Para comunicação e pôster, com exceção da primeira edição, há maior participação de mulheres do que de homens, com destaque novamente para a VI SIA que contou com a participação de três pessoas trans. Sobre organizadories, também foi variada essa participação: mais equilibrada (II, IV), mais mulheres (I, III, V) ou mais homens (VI).

De maneira geral até a II SA as discussões de gênero e ativismo político não eram as principais preocupações do evento, e, ainda assim, há equilíbrio na participação de mulheres e homens. Na IV edição, chama atenção o número muito maior de homens como palestrantes convidados, mas a participação nas comunicações manteve-se equilibrada. Nessa edição, houve uma tentativa de integrar palestrantes e estudantes em sessões temáticas. Isso alerta para uma questão importante, já discutida em outros lugares: questão de gênero não é a única questão identitária e de diversidade que perpassa a Arqueologia, outras questões são igualmente importantes, porém mais difíceis de contabilizar a partir dos dados oficiais, como identidade étnico-racial ou de orientação sexual.

Por exemplo, na V SIA houve a abertura para graduandes apresentarem comunicações orais, o que pode ter incentivado a participação indígena (com fala ao invés de escrita, além de trabalho audiovisual). Foi a primeira edição com participação indígena: um estudante Munduruku do Pará, e o Coletivo Audiovisual Laklãnõ Xokleng, de Santa Catarina. Isso também pode ser visto na VI edição, em que a maior parte des organizadories é homem, mas foi a edição mais inclusiva (do ponto de vista de temas e pessoas) até o momento: ao menos cinco participantes indígenas, dois quilombolas e três pessoas trans. É preciso refletir também que, mesmo sendo só homens que organizem um evento ou que sejam os palestrantes principais, não necessariamente o público e apresentadories de trabalhos não possam ser em sua maioria mulheres ou diversos em outros aspectos identitários.

A participação por região, observada na Fig. 4, é justamente o aspecto que fez com que esse evento assumisse sua importância nacional. Os dados são para comunicação oral e de pôsteres, mas é importante ressaltar que muitos participantes de outras regiões vêm também como ouvintes. De qualquer maneira, até a II edição entre $83 \%$ e $85 \%$ do público era da região Sudeste, compreensível já que o encontro é em São Paulo. A partir da III edição, no entanto, a participação do Sudeste caiu para $65 \%$, acompanhada do crescimento de participação de outras regiões, principalmente a Sul. A partir da IV edição, a participação do Sudeste ficou entre $55 \%$ e $59 \%$, com destaque para a participação do Nordeste, que marca presença por causa de alunes da Universidade Federal do Piauí (UFPI) e Universidade Federal do Vale do São Francisco (Univasf). 
Surgimento e consolidação da Semana Internacional de Arqueologia Discentes MAE-USP: uma reflexão R. Museu Arq. Etn., 34: 1-25, 2020.
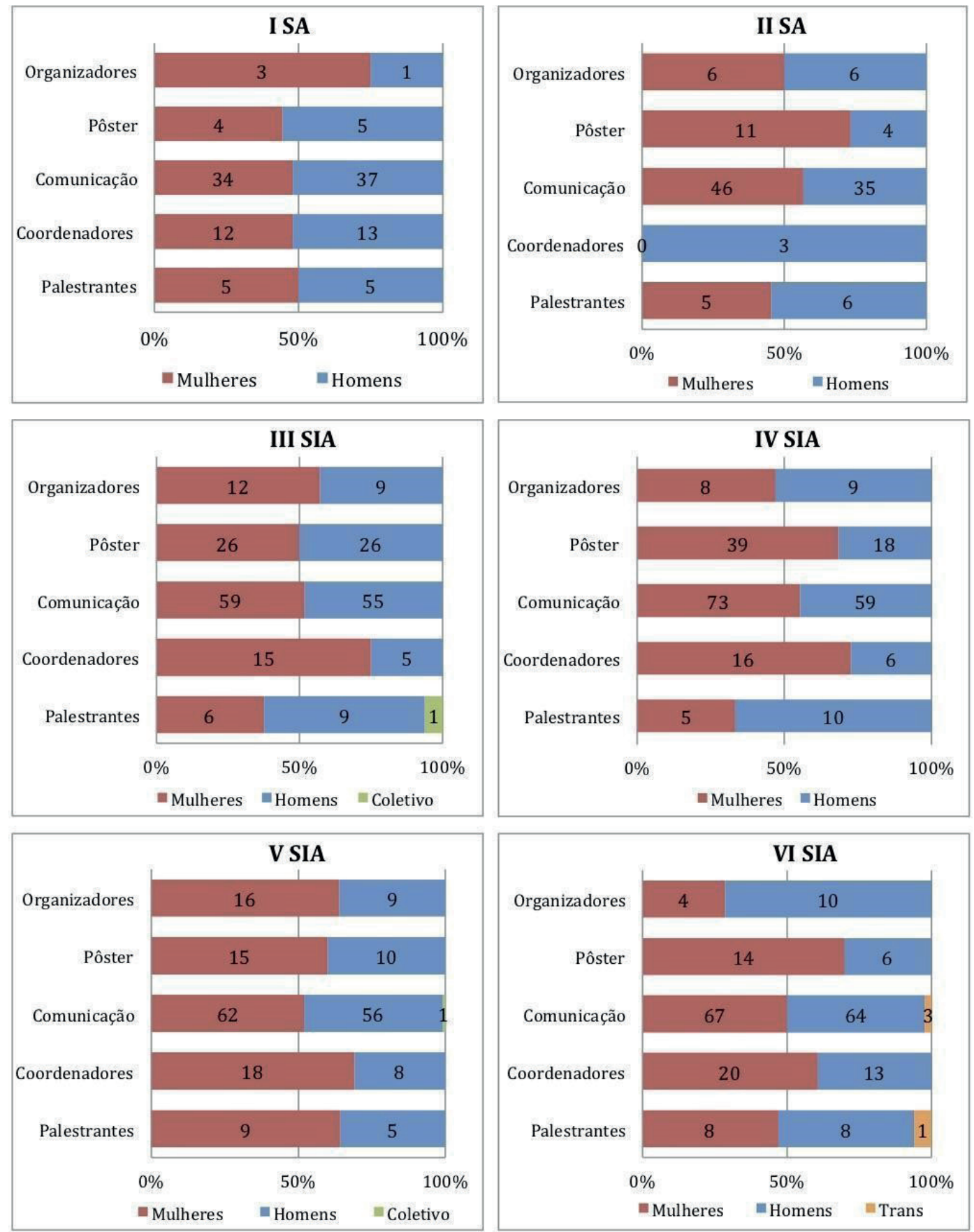

Fig. 3. Gráficos comparativos da participação de mulheres, homens, coletivos e pessoas trans em cada edição do evento. 


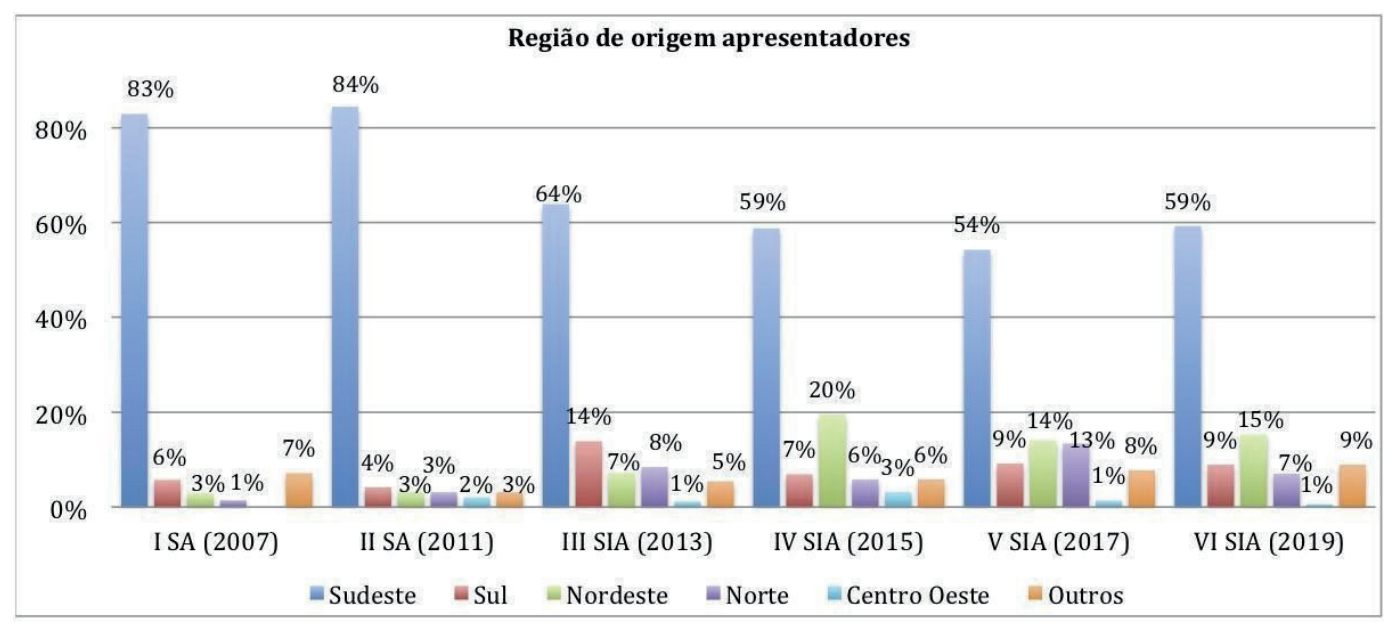

Fig. 4. Gráfico comparativo da participação de apresentadories de comunicações e pôsteres por região em cada edição do evento. A categoria "outros" inclui pessoas filiadas a empresas de contrato, instituições estrangeiras ou sem filiação.

O crescimento da SIA aconteceu com o estabelecimento de edições periódicas, e a sua importância na agenda de eventos nacionais ${ }^{13}$ foi confirmada pela presença de público oriundo de vários lugares do país e pelas avaliações das agências de fomento.

Quanto a diversidade presente nas edições da SIA reflete a diversidade da Arqueologia no Brasil como um todo e quanto a diversidade na Arqueologia reflete a diversidade na sociedade nacional são questões que ainda precisam ser respondidas com dados mais consistentes e sistemáticos.

13 Alguns eventos de arqueologia organizados por discentes pelo país são:

Encontro Regional dos Estudantes de Arqueologia do Nordeste do Brasil (desde 2009, com periodicidade anual, contexto temporal muito próximo da primeira ediccão da SIA); Semana Acadêmica de Arqueologia da Universidade Federal do Rio Grande (FURG) (décima edição em 2019, contexto temporal também próximo da primeira edição da SIA); Semana Acadêmica de Arqueologia da Federal de Rondônia (desde 2011); Semana de Antropologia e Arqueologia da Universidade Federal de Minas Gerais (UFMG) (desde 2012); Semana de Arqueologia da Universidade Estadual do Rio Janeiro (desde 2014, periodicidade anual); Semana de Arqueologia da Universidade Federal do Rio de Janeiro (desde 2015); Semana de Arqueologia da Universidade Federal de Sergipe (desde 2015); I Semana de Arqueologia da Universidade Federal do Pernambuco (UFPE) (desde 2018); Encontro Nacional de Arqueologia (Enearq) (desde 2018); Simpósio de Arqueologia e Patrimônio na Universidade Federal do Vale do São Francisco (desde 2019); Semana de Arqueologia da Universidade Federal do Piauí (desde 2018).

\section{Contribuições para a formação de estudantes}

A participação em eventos científicos permite uma gama de experiências tanto para profissionais como para estudantes em formação: a avaliação por pares, o aperfeiçoamento de trabalhos e apresentações, o conhecimento do panorama atual das pesquisas e novas abordagens, a comunicação informal entre pares, entre outros (Cendón, Campello \& Kremer 2000). Essas experiências são importantes para o desenvolvimento de habilidades necessárias em carreiras acadêmicas e científicas, que também podem ser utilizadas em outras áreas de atuação (as chamadas transferable skills), como a organização/administração do tempo e atividades de pesquisa, o desenvolvimento de redes de relacionamento profissional (networking) e a comunicação com diferentes públicos (Tomazou \& Powell 2007: 724). A organização de encontros por estudantes é um dos meios para o desenvolvimento dessas habilidades e experiências. Um bom exemplo disso é a Cambridge Annual Student Archaeology Conference, organizada anualmente pelo corpo estudantil da Universidade de Cambridge, Inglaterra, desde 2017, e que se consolida no calendário estudantil de atividades internacionais. 
Conferências de prestígio para a apresentação de trabalhos, como as reuniões da $S A B$, podem ser bastante intimidantes para estudantes no início de sua formação, que muitas vezes devem expor suas pesquisas junto a profissionais de renome. Além disso, esses congressos normalmente têm normas mais rígidas de inscrição (como ser associado de alguma sociedade científica ou ter determinado nível de formação) e muitas vezes são distantes do local de residência de muites estudantes.

É por isso que quando esses espaços são organizados de forma autônoma por estudantes, eles podem ser um meio mais convidativo para praticar habilidades de comunicação, expor dúvidas e conversar com outres estudantes que compartilham das mesmas preocupações e inseguranças. A própria organização de um evento científico auxilia estudantes a desenvolverem outros tipos de habilidades que serão importantes em suas futuras carreiras, seja na academia ou fora dela como a elaboração de projetos para pedidos de financiamento, administração de recursos financeiros, seleção de palestrantes, revisão dos trabalhos submetidos, entre outros (Tomazou \& Powell 2007: 724).

No caso da SIA, aprender a trabalhar coletivamente na organização com colegas, funcionáries e professories do MAE é uma das experiências positivas e um dos desafios mais ressaltados por organizadories de todas as edições. A distribuição mais equitativa de tarefas de organização (para não sobrecarregar poucas pessoas) e exercitar tomada de decisões coletivas e respeito às opiniões de colegas fazem parte dessas experiências. A participação recorrente de uma mesma pessoa como organizadore ou colaboradore em mais de uma edição é um indicativo da relevância dessa vivência.

Em todas as edições, o envolvimento de estudantes organizadories não é homogênea, na I SA há relatos da empolgação inicial de vários discentes, porém somente quatro pessoas aparecem como responsáveis pelo desenvolvimento do evento. $\mathrm{O}$ fato de se constituírem pequenas comissões com poucos alunos assumindo a responsabilidade até o final é uma questão que perpassa todas as edições até os dias atuais. $\mathrm{O}$ trabalho voluntário acaba sendo experimentado de maneira diferente pelas pessoas, as dificuldades e demandas das pesquisas individuais, além das habilidades específicas de cada um, moldam o grau de envolvimento e as dinâmicas das relações durante o processo organizatório. O ideal é que se construa uma equipe onde a divisão de trabalho seja equivalente entre todos, mas isso sempre dependerá das relações construídas por cada grupo.

A organização coletiva de estudantes e a transmissão de suas experiências de uma edição para a outra, assim como para a organização de outros encontros estudantis (pela disponibilização do Guia de Organização da SIA), são legados que esperamos inspirar e auxiliar outros coletivos estudantis em seus próprios eventos. É importante ressaltar, no entanto, que esses encontros não precisam necessariamente ter grandes proporções ou caráter internacional para que as questões aqui apresentadas possam ser desenvolvidas. É justamente a diversidade de espaços e oportunidades para discussão de diferentes temas que contribuem para o desenvolvimento de habilidades acadêmicas e científicas em diferentes aspectos, já que cada evento pode ser voltado para um público ou temática específica:

Most importantly, young scientists need not wait for opportunities to organize and communicate to be provided for them, nor must they arrange an international conference for every subject - events can be equally successful as small, simple and local (Tomazou \& Powell 2007: 726) ${ }^{14}$.

Organizar eventos de forma coletiva como estudantes possibilita ir além dos limites tradicionais da instituição. Permite aprofundar e complementar temas abordados pelo corpo docente, ou mesmo extrapolar e buscar temas que ainda não foram contemplados. Além disso,

14 Tradução nossa: Mais importante, jovens cientistas não precisam esperar que oportunidades para organizar e comunicar sejam apresentadas para eles, nem precisam providenciar conferências internacionais para cada assunto - eventos podem ter igual sucesso se forem pequenos, simples e locais. 
cria espaços de diálogos nas diferentes esferas da instituição, exercita a autonomia decisória, autoorganização e alternativas de aprendizagem para além do tema de pesquisa. Dessa forma a SIA pode ser compreendida como espaço formador dentro do MAE-USP, que integra alunes de diferentes linhas de pesquisas e reforça o diálogo entre os estudantes, professories e funcionáries.

\section{Considerações finais}

A proposta do evento surgiu devido à necessidade de se conhecer mais os trabalhos de colegas de diferentes áreas do MAE e para preencher lacunas teóricas e metodológicas ausentes durante os cursos de pós-graduação. Encontros desse tipo ganharam importância por permitirem que estudantes de graduação e pós-graduação desenvolvam competências e habilidades úteis para sua vida profissional, como autonomia, desenvolvimento de projeto, captação de recursos e gerenciamento de crises.

A SIA é organizada pelo corpo discente do MAE-USP de forma voluntária, no qual desde coordenação, temas, palestrantes, espaço e outros mínimos detalhes são decididos de forma coletiva. A comissão organizadora é composta por estudantes da pós-graduação e alguns de graduação vinculados ao Museu.

Em termos internos, a grande contribuição da SIA é na vida cotidiana do MAE-USP, ao aproximar discentes, docentes e funcionáries. Em uma perspectiva externa ao Museu, a SIA se consolidou como um grande encontro nacional, com espaço aberto a estudantes de todo o país e a vinda de palestrantes de diferentes instituições e países que tratam de temas que interessam diretamente os discentes.

Estudantes atuam como protagonistas em todas as etapas de elaboração da SIA: eles são autores e estão no centro de todos os processos. A construção desse tipo de espaço é um importante instrumento de comunicação e relacionamento, mas vai muito além disso: é também um local de formação não linear e de posicionamento político perante instituições, colegas e a própria prática arqueológica.
À medida que mais eventos como esse passam a ser organizados, maior será a pluralidade dentro das ciências arqueológicas.

Fazer parte da organização está se consolidando como espaço de aprendizagem de outras temáticas arqueológicas, de relação com seus pares, de gestão de pessoas, agendas, captação de recursos e gerenciamento da saúde emocional.

O sucesso de debate e público em todas as edições só foi possível graças ao financiamento das agências de fomento e do programa de pós-graduação e apoio da própria USP. Espaços como esse proporcionam um lugar seguro para debates entre profissionais e estudantes, além do baixo custo de investimento por parte de alunes. Dessa forma, democratiza o acesso a temas atuais conflitantes da Arqueologia e estimula o diálogo entre pares.

Foi um trajeto longo, trabalhoso e gratificante para a maior parte des organizadories de todas as edições do evento. Caminho que pode e deve ser trilhado por outras comunidades discentes. Este artigo teve a finalidade de refletir sobre as primeiras seis edições da Semana Internacional de Arqueologia Discentes MAE-USP, além de servir como um registro parcial das atividades até então. Esperamos que ainda se realizem muitas outras edições da SIA, e que o corpo estudantil se mantenha resiliente e organizado.

\section{Agradecimentos}

Dedicamos essa análise para todes colegas estudantes do MAE-USP que, ao longo das seis edições, se envolveram e fizeram a SIA acontecer e crescer. Agradecemos também às professoras e aos professores que aceitaram o convite para coordenar a Semana, às servidoras e aos servidores técnicas(os) do MAE (especialmente ao Educativo, Dape, Audiovisual, Administrativo, Financeiro e Diretoria). Agradecemos a Capes, CNPQ, Fapesp e USP pelo financiamento nas diferentes edições e às/aos pareceristas anônimos/as que contribuíram para o artigo. 
Surgimento e consolidação da Semana Internacional de Arqueologia Discentes MAE-USP: uma reflexão R. Museu Arq. Etn., 34: 1-25, 2020.

BRANDÃO, K. et al. Emergence and consolidation of the International Archaeology Week MAE-USP Students: some considerations. R. Museu Arq. Etn. 34: 1-25, 2020.

Abstract: This article discusses and reflects on the creation and consolidation of the International Week of Archeology Students MAE/USP (SIA), which began in 2007 and happens every two years. Organized in an open and collaborative way by museum students, SIA has become a space for articulation and exchange of knowledge and experiences, playing a fundamental role in the education of future professionals engaged in science and the management of archaeological heritage in the context of Brazilian archaeology. Over its various editions, the event has acquired professional recognition and achieved international lengths, with the creation of a dynamic and democratic protocol for students to work together and with greater institutional insertion. An organization made by students and aimed at interested people in general, the SIA has enhanced its open spirit and growing dialogue with different human collectives that have been demanding new practices and attitudes of archaeological practice. Through interviews, questionnaires, documentation reviews and our personal experience, we provide here a look at the history of SIA and its role in the academic trajectory of students and of the museum as a whole. We hope that this reflection contributes to stimulating the continuity and emergence of other similar events across the country.

Keywords: Scientific events; Archaeology; Students; Organization.

\section{Referências bibliográficas}

Cendón, B.V.; Campello, B.S.; Kremer, J.M. 2000. Fontes de informação para pesquisadores e profissionais. Editora UFMG, Belo Horizonte.

Corpas M.; et al. 2008. Ten simple rules for organizing a scientific meeting. PlosCompBiol, 4(6): 1-3.

Faria, I. et al. 2019. Criação e organização de evento acadêmico médico: I Encontro Acadêmico de Gastroenterologia de Minas Gerais. Rev Med Minas Gerais, 29: 16-22.

Figuti, L.; Plens, C.; Nishida, P. (Orgs.). 2009. Anais da I Semana de Arqueologia - MAE: Revista do Museu de Arqueologia e Etnologia, supl. 8.

Fleming, M.I.A. (Org.) 2011. Anais da II Semana de Arqueologia - MAE: Revista do Museu de Arqueologia e Etnologia, supl. 11.
Nishida, P.; Plens, C. (Orgs.), 2007. Arquivos da Semana Internacional de Arqueologia Discentes MAE-USP. Disponível em: <https://bit. ly/2EhSuhT $>$. Acesso em: 24/07/2020.

Paz, J.R.L. et al. 2014. A importância da organização de eventos acadêmicos na formação do biólogo: a iniciativa do biovertentes. Em Extensão, 13: 51-60.

Porto, V.C.; et al. (Orgs.). 2019. Arqueologia hoje: tendências e debates. Disponível em: <https://bit. ly/2ZWuI2W>. Acesso em: 27/07/2020.

Pouget, F.; Carvalho, A.V. (Orgs.). 2019. Arqueologia Queer: Revista de Arqueologia Pública, v. 13, n. 1.

Ribeiro, L. (Org.). 2017. Dossiê Arqueologia e Crítica Feminista no Brasil - uma apresentação. Revista de Arqueologia, 30: 3-7. 
Kelly Brandão, Aline Oliveira, Meliam Gaspar, Maurício André da Silva, Renato Saad Panunzio, Renata Estevam, Emerson Nobre e Elaine Farias Veloso Hirata

Tomazou, E.M.; Powell, G.T. 2007. Look who's talking too: graduates developing skills through communication. Nature Reviews Genetics, 8: 724-726.

Ulguim, P. 2019. Analisando a programação do Congresso da Sociedade de Arqueologia Brasileira e outras coisas do gênero. Disponível em: <https:// bit.ly/2D043to >. Acesso em: 24/07/2020.

Wesolowski, V. et al. (Orgs.). 2015. Anais da III Semana Internacional de Arquelogia "André Pennin": Revista do Museu de Arqueologia e Etnologia, supl. 20. 